\title{
Factibilidad de Gestión de los Conocimientos Tradicionales desde el Hacer de la Cultura sobre el Territorio
}

\author{
Feasibility of Managing Traditional Knowledge from the Culture on the Territory \\ Catherine Sylvia Rosas-Bustos \\ crosas@unap.cl @ https://orcid.org/0000-0002-3999-3463 \\ Facultad de Ingeniería y Arquitectura. Universidad Arturo Prat (UNAP), Chile. \\ Universidad Arturo Prat, Iquique. Código Postal: 1110939.
}

\section{INFO ARTÍCULO}

Recibido: 14-03-2020

Revisado: 01-06-2020

Aceptado: 05-06-2020

\section{PALABRAS CLAVE}

Conocimientos Tradicionales

Gestión

Patrimonio

Comunidades Rurales

Comunidades Indígenas

\section{KEYWORDS}

Traditional Knowledge

Management

Heritage

Rural Communities

Indigenous Communities

\section{RESUMEN}

En el contexto de la globalidad, se ha producido una migración sostenida del campo a la ciudad, que ha generado una pérdida de los conocimientos tradicionales de las comunidades rurales e indígenas Latinoamericanas.

Frente a la necesidad de recuperar estos conocimientos, y en este requerimiento administrar eficientemente los recursos, se propuso como objetivo, crear una estrategia inicial, para la evaluación de factibilidad de gestión de estos saberes. Para esto se trabajó, en dos casos de estudio, el "Sistema Constructivo de viviendas de barro y paja, de la comuna de Colchane, región de Tarapacá norte de Chile.", y la "Mesa de mujeres rurales de la comuna de Licantén, región del Maule, sur de Chile.

En estos casos se verificó, si existe aún un sistema de actividades e interconexión entre conocimientos, lo cual nos permitió corroborar la factibilidad de gestión de estos saberes, como patrimonio y recurso para el desarrollo sostenible de las comunidades en su territorio.

\begin{abstract}
In the context of globality, there has been a sustained migration from the countryside to the city, which has generated a loss of traditional knowledge of rural and indigenous Latin American communities.

Faced with the need to recover this knowledge, and in this requirement to efficiently manage resources, the objective was to create an initial strategy for evaluating the feasibility of managing this knowledge. For this, two "case studies" were carried out, the "Construction System of mud and straw houses, in the commune of Colchane, Tarapacá region, northern Chile.", And the "Rural Women's Table in the commune of Licantén, Maule region, southern Chile.

In these cases, it was verified if there is still a system of activities and interconnection between knowledge, which allowed us to corroborate the feasibility of managing this knowledge, as heritage and resource for the sustainable development of the communities in its territory.
\end{abstract}




\section{INTRODUCCIÓN}

Cuando nos enfrentamos a la necesidad de activar y gestionar un conocimiento tácito ${ }^{1}$ como son los conocimientos tradicionales (de ahora en adelante, C.T.) de las comunidades, considerando a estos como un patrimonio y un recurso para su desarrollo. Nos debemos disponer en la búsqueda de estrategias de gestión, que deban considerar lo que significan estos saberes, para su comunidad como fundamento de acción sobre su territorio.

Vislumbrando también, cuál es el potencial lugar, que tiene el o los C.T. en el sistema de la globalidad, la cual considera que estamos insertos en una sociedad de conocimiento (Drucker, 1969).

Los C.T como patrimonio, es un bien potencial de intercambio tanto en la conformación local de las comunidades, como en el sistema global mayor, ya que un «patrimonio histórico como recurso económico está garantizado de cualquier manera. La demanda de bienes culturales en todo el mundo crece a gran ritmo no sólo en los viejos países más ricos, sino también en los países en desarrollo» (Ballart Tresserras, 2001, p. 123-124).

Esta demanda de bienes culturales se ha sostenido en el tiempo, propiciada por la fuerte globalización de la economía, la cual presenta un panorama de manejos industriales territoriales de gran escala, generando un alto impacto en pequeñas comunidades rurales e indígenas.

Considerando que a partir de este proceso se generan nuevas escalas de organización industrial con efectos territoriales. Ejemplos de esta nueva economía son la deslocalización de la manufactura, la descentralización y diversificación de actividades, los nuevos factores de localización o el continuo flujo de bienes y servicios (Soria, 2012, p. 58).

Las comunidades rurales e indígenas están expuestas al ámbito industrial de la globalidad, como definen Goya, Vrsalovic y Sainz (2010), donde presentan a este como, un sistema de facilidad de conexión y desconexión, no obstante, propicia la creación de los "hoyos negros"2 y el "cuarto mundo"3, dejando a comunidades desconectadas de las redes del informacionalismo global, ya que no son valiosos productores ni tampoco, potenciales consumidores, frente al sistema económico mundial.

Esta desconexión, ha sido agravadas por la sostenida migración de estas comunidades desde el campo a la ciudad, pues en Latinoamérica, en el año 2009, según la CEPAL, Argentina, Brasil y Chile, tienen niveles de urbanización superiores al $80 \%$, Costa Rica y México 60\% y 70\%, respectivamente, Bolivia y Guatemala presentan niveles inferiores.

La sostenida migración, ha afectado el desarrollo sostenible de las comunidades, considerando que la desconexión con su territorio ha propiciado la pérdida de estos C.T., está perdida es también, la pérdida de una visión de desarrollo común, de unión y reciprocidad con el entorno. Esta visión hoy, resulta urgente de recuperar y activar, dentro de nuestro contexto global ambiental, social, cultural y económico.

Considerando que la perspectiva del sistema mundial, se ha hecho insostenible, evidenciado la necesidad urgente, de recuperar la relación armoniosa que debe mantenerse con el medio ambiente, para nuestra sobrevivencia como especie.

Este contexto crítico, lo plantea Boege (2008), manifestando que estamos viviendo un proceso de globalización y universalización de la mercancía, presenciamos un peligroso quiebre en las interacciones de histórica duración entre la comunidad indígena y la naturaleza. En considerables situaciones, se genera un

1. «El conocimiento tácito, es aquel que toda organización tiene, pero que no queda plasmado ni registrado en lugar alguno, estando totalmente ligado al grupo de personas que componen la organización en cada momento» (Bustelo y Amarilla, 2001, p. 226).

2. «Claro está que las distancias no se han truncado de la misma manera en todas las regiones del mundo, lo cual resulta en una nueva jerarquía del espacio cibernético: las "ciudades globales" ocupan la cúspide de la pirámide, estrechamente interconectadas por cables de fibra óptica y transportes aéreos y terrestres que atraviesan las fronteras a alta velocidad, mientras que en la base hay regiones enteras e incluso continentes -como África o Asia Central, por ejemplo- que constituyen 'agujeros negros' en el universo informático (Castells, 1997), sin ninguna conexión significativa con el resto del mundo y entre sí» (Sachs, 2002, p. 76).

3. «En un plano más general, explorar por ejemplo qué comentarlos críticos sobre el orden mundial comporta el que los pueblos indígenas y tribales articulen sus demandas autoconstruyéndose como “Cuarto Mundo"» (Briones, 1996, p. 132). 
desvanecimiento de la diversidad cultural y de sus valores, a favor de sociedades que se instalan en la monocultura global.

Este autor también plantea, que la economía de mercado a escala global, ha sido sostenida por la sobreexplotación y expoliación cortoplacista de los recursos naturales, lo que ha afectado gravemente al medio ambiente, donde esta monocultura ha sido desarrollada en una conciencia que no integra a la sostenibilidad.

Frente a este contexto, se desarrolla una propuesta metodológica, que plantea el objetivo de crear una táctica que nos permita gestionar los C.T., como patrimonio y recurso para sus comunidades. Mediante la definición de una estrategia para evaluar la factibilidad que tiene cada uno de los C.T. para ser gestionado e implementado en la recuperación cultural y territorial de estas comunidades.

\section{PROBLEMÁTICA Y PERSPECTIVA}

Generar acciones para conservar esta diversidad cultural que se desvanece con el impacto de este mercado global, es un requerimiento urgente, siendo necesario crear estrategias y modelos que recuperen el valor de los C.T., trabajando en la conversión de estos en insumos, que se constituyan como recursos, para aportar a la reconexión de estas comunidades, a un sistema de intercambio justo. Buscando los distintos caminos de comprensión para restaurar un desarrollo propio, desde su propia forma de ser comunidad sobre el territorio.

En esta situación de búsqueda, se propone comprender la oportunidad que guarda, el contexto complejo de la globalización, considerando que lo que los C.T., pueden aportar a la nutrición de esta era de la información.

Esta oportunidad sitúa a los C.T., como una potencial guía, integrando lo definido por Morín (2006) donde un conocimiento debe ser capaz de admitir las circunstancias de la acción y la acción misma, debiendo lograr contextualizar en un antes y un durante la acción generada, comprendiendo la compleja realidad que nos presenta la globalización, este patrimonio, puede aportar con sus claves, ya que es un conocimiento que comprende la complejidad requerida.

Independiente a la oportunidad que pueden tener los C.T. en los requerimientos que hoy nos muestra la globalización, nos queda dimensionar la sostenida migración de las comunidades rurales e indígenas a las distintas áreas urbanas dentro de Latinoamérica, fenómeno que no ha decrecido en el tiempo, «las cifras ratifican, por otra parte, que no hay procesos de contraurbanización en curso, pues persiste la transferencia neta de población del campo a la ciudad» (Rodríguez, 2008, p. 148).

Esto ha generado una pérdida de valor del patrimonio cultural rural e indígena, que ha afectado considerablemente a los C.T., generar tácticas para revertir esta situación es una necesidad urgente.

Esta pérdida de patrimonio, ha generado distintas estrategias de salvaguarda, en Chile las inversiones en el área de patrimonio y cultura, que se han desarrollado, para apoyar a las minorías locales rurales e indígenas, han sido mediante el Fondo de Desarrollo de las Artes y la Cultura (FONDART) 4 .

Estos fondos no obedecen a estrategias de desarrollo cultural en la escala local, generando que estas inversiones operen de forma aislada y por decisión de la solicitud de la comunidad o solo por iniciativa de los cargos políticos que funcionan en cada uno de los periodos electorales.

Esta figura ha sostenido una constante inversión, por parte de las comunidades y del estado, sin lograr un trabajo sistémico que permita una sostenibilidad en el desarrollo cultural y la conservación del patrimonio local.

Desde esta mirada, para generar este desarrollo de forma sistémica, se deben crear formas de gestión y evaluaciones previas, mediante las cuales se obtenga información clave, para guiarnos en saber de antemano el impacto de una inversión, considerando la potencial incorporación de los C.T., como un recurso para el desarrollo local de las comunidades.

4. FONDART cual fue creado el año 1992 mediante la ley № 19.891, como un aporte público, orientados a beneficiar a las comunidades y corporaciones $\sin$ fin de lucro. (https://www.fondosdecultura.cl/) 
Estas estrategias de evaluación deben ser capaces de determinar la factibilidad de cada C.T., su aceptabilidad y su conveniencia, de ser recuperados y puestos en valor dentro de una red de intercambio, como según propone Varela (2001) se deben evaluar la existencia de recursos, la disposición y voluntad de los grupos o comunidades en este caso.

Es necesario evaluar la factibilidad de inversión de recursos, que se requieren para generar una activación y sostenibilidad instrumental de su valor, para lograr un aporte al fortalecimiento de la cultura de estas comunidades y generar un aporte al sistema mayor dentro del cual se inserta.

Considerando que la factibilidad, dentro del proceso de gestión y la planificación es para que se implemente y para ver que efectivamente se está implementando, hay que ejercer un control preventivo sobre su realización, además de organizar en base a esos procesos, definiendo la estructura organizativa que la propiciará (Llanes-Font, Isaac-Godínez, Moreno-PinoI y García-Vidal, 2014, p. 257).

Vislumbrar esta estructura organizativa, para hacer efectivo el proceso de gestión, es una acción previa necesaria, para poder determinar donde cada comunidad debe invertir sus energías para recuperar y mantener el desarrollo de su cultura. Considerando a este saber cómo un recurso, que los puede resituar en este modelo de civilización que conforma esta sociedad de conocimiento y la globalidad.

\section{TEORÍA}

Dentro del contexto de esta demanda, continuamos con la búsqueda de una definición instrumental de los C.T., que nos permita determinar su valor operativo para ser gestionado, para esto se considera la propuesta donde De la Cruz (2005), citado por Bolvito, Macario, Sandoval (2008) «hace una clasificación de los tipos de conocimientos tradicionales, la cual se presenta a continuación: Conocimientos teóricos...Conocimientos prácticos...Conocimientos de procesos...» (p. 121).

Dentro de esta definición se extienden estructuras potenciales para comprender el proceso de evaluación de factibilidad de gestión de los C.T., pues condice su forma dentro de los ámbitos del "ser" de la comunidad, el "hacer" en su acción sobre su territorio, más "el saber hacer" que implica la creación de nuevos conocimientos, más considera los procesos de su desarrollo y actualización.

Estas estructuras han generado la conservación de los C.T. en el tiempo, comprendiendo los ciclos culturales sostenidos de forma histórica, la articulación de estas estructuras es la encargada de que este patrimonio cultural sea un insumo para el desarrollo de su comunidad. Considerándolo, dentro del ámbito de la patrimonialización y lo que significa la gestión de un C.T., es un patrimonio que surge desde el sentido del "ser" de una comunidad, que bien se dimensiona desde su cosmovisión.

Donde, el conocimiento que genera la cosmovisión, traducido generalmente en un sistema de mitos y ritos, no depende de una aproximación racional al mundo; es un tipo de conocimiento emocional e intuitivo, cuyo sentido es esencialmente simbólico, que se tornará en cierta medida racional en cuanto comienza a formar un pensamiento, dada la necesidad de cada comunidad humana de interactuar en el mundo concreto; de allí que los primeros sistemas de pensamiento humanos estuvieron entrelazados a su cosmovisión, como parte de su concepción sacralizada del universo (Restrepo, 1998, p. 34).

Así dentro de lo que significa la cosmovisión, los C.T., son parte de la forma de ser de la comunidad, esta relación dentro del ámbito de la gestión, se traduce en la voluntad de ser, directamente en la misión ${ }^{5}$ de una organización o como en este caso de la comunidad.

5. La misión de una empresa es el motivo por el que existe dicha empresa, su razón de ser. Indica la actividad que realiza la empresa. Suele plasmarse en una declaración escrita (una frase o un párrafo) que refleja la razón de ser de la empresa. (www.economipedia.com). 
Esta misión que es parte del "ser", tiene desde sus principios de valorización de sí mismos y respecto a su entorno, considerando que ser comunidad es un «conjunto de personas vinculadas por características o intereses comunes». (www.rae.es)

La dimensión simbólica que van configurando estos intereses comunes, donde el «conocimiento local e indígena alude a los cuerpos de conocimientos, prácticas y representaciones, de naturaleza acumulativa y compleja, preservados y desarrollados por pueblos con extensas historias de interacción con el medio ambiente natural». (UNESCO, 2003)

La gestión histórica de los C.T., generada en la interacción que han tenido las comunidades de forma sostenida con su medio ambiente, ha creado una teoría de existencia en reciprocidad y complementariedad, para la subsistencia de cada ser vivo. Esta teoría de subsistencia es la que ha guardado el sentido complejo de este patrimonio y guarda también en este hecho, su potencialidad como recurso actual para el desarrollo de esta nueva era del conocimiento y la información.

Ya que como saber, este está conformado por las creencias (cosmos), el sistema de conocimientos (corpus) y el conjunto de prácticas productivas (praxis) que hacen posible comprender cabalmente las relaciones que se establecen en el uso o manejo de la naturaleza por parte de las comunidades campesinas en sus procesos de producción agropecuaria desde los cuales se configuran sus territorios (Cárdenas Grajales, 2010, p. 2).

Dimensionar las relaciones que se establecen en el manejo del entorno de estas comunidades, es uno de los ejercicios vitales en el ámbito de su actual gestión. Donde el valor de estas relaciones, se encuentra cimentado en los intereses comunes que transforman a la comunidad en una organización, la cual, siendo organización, desde el área de la gestión, implica que «son diferentes entre sí en función de los recursos y capacidades que poseen en un momento determinado. Estos recursos y capacidades no están disponibles para todas las empresas en las mismas condiciones. Esto explica sus diferencias de rentabilidad». (Fundación Iberoamericana del Conocimiento, 2010).

En esta área de gestión estratégica como disciplina, es la "Teoría de Recursos y Capacidades", que se presenta en la anterior definición, la que puede ser aplicada al patrimonio, esta teoría puede potenciar a los C.T., como un recurso de valor diferenciador, frente a un contexto de intercambio, al identificar a una comunidad como organización. Más, frente a la necesidad de que las comunidades puedan administrar eficientemente sus recursos, en el ámbito de la gestión del patrimonio, nos enfrentamos al concepto de rentabilidad de una inversión.

Que es la capacidad que tiene una empresa para poder generar los beneficios suficientes, en relación con sus ventas, activos o recursos propios, para ser considerada rentable. Es decir, que la diferencia entre sus ingresos y sus gastos es suficiente como para mantenerse en el tiempo de manera sostenible y seguir creciendo (www. mytriplea.com, diccionario financiero).

Pero esta rentabilidad cubre no solo los ámbitos económicos, sino de forma implícita requiere una rentabilidad social, cultural y ambiental, para comprender retornos efectivos de una movilidad de recursos para la gestión de este patrimonio. Al visualizar esta rentabilidad en todos estos ámbitos, la cual, como fenómeno conjunto, sostiene el ciclo de producción del patrimonio, nos permite comprender la posibilidad o factibilidad de gestión que tiene cada saber tradicional dentro de una comunidad.

Dimensionar esta rentabilidad conjunta, es comprender el dialogo de ser comunidad, que, en este caso, es un "ser" que se comprende como parte de su entorno, el cual esta significado desde su cosmovisión.

Pues el hombre no ha tejido la red de la tierra, es solo una hebra de ella. Todo lo que haga a la red se lo hará a sí mismo. Lo que le ocurre a la tierra les ocurrirá a los hijos de la tierra. Lo sabemos. Todas las cosas están relacionadas como la sangre que une a la familia (Fragmentos de la carta del Jefe de la Tribu Sewanish, dirigida al Presidente de los Estados Unidos, hace ciento veinte años) (Lira, 2010, p. 1). 
Este "ser" comunidad y comunión con su entorno, se observa en cada acción que realiza la comunidad con su territorio, donde surge el "hacer" como una continuidad de esta visión", que tiene la comunidad como organización, esta continuidad es la que implica también la requerida evaluación dentro de la factibilidad de gestión de un conocimiento tradicional.

Este encadenamiento general, deja establecido el soporte para conformar el ciclo de producción que sostiene a este conocimiento, que permite la gestión implícita del saber tradicional como patrimonio, ya que para "hacer" hay que "saber hacer".

Esto define la forma en que una comunidad enuncia su accionar y ordena sus procesos para habitar su territorio, actualizando sus conocimientos, dejando implícita su histórica estrategia contenida en la estructura de su propia racionalidad.

Pues la estructura del proceso de toma de decisiones tiene varios elementos como lo son: Escenario o espacio bio-geográfico donde se toman decisiones; objetivos de producción y reproducción que tiene que ser logrados a través de la ejecución de las prácticas sociales, para la realización de las estrategias sociales que emergen de la formulación de problemas; y todo esto, realizado bajo una racionalidad contenida en la lengua respectiva (Romero, 2006, p. 191.).

Desde esta premisa, es necesario entender el concepto de la racionalidad histórica definida por el antropólogo Hugo Romero Bedregal (1980), considerándola como la lógica interna y aplicada de un sistema en general, donde la racionalidad histórica de un sistema entrega el soporte a la praxis de su comunidad, que se interrelaciona y transforma mutuamente en y con su espacio físico-natural, por lo cual en su territorio. Posteriormente al desarrollar estrategias sociales que transmutan a relaciones sociales y normas de comportamiento.

Esta definición planteada, nos entrega las bases de la construcción de este patrimonio dentro de las comunidades que han interaccionado de forma continua con su territorio, como plantea Romero Bedregal (1980), significándolo e incorporándolo, como un recurso para la sostenibilidad de su espíritu y subsistencia, como unidades organizadas con su propia forma cultural.

Pues como plantea Suarez (2012) citando a Lefebvre (1991), donde cada modo de producción (...) produce un espacio, su propio espacio, su propia práctica espacial, esto genera sus formas espaciales con su propio y particular tiempo o tiempos.

Esta propia forma «es un proceso voluntario de incorporación de valores socialmente construidos, contenido en el espacio-tiempo de una sociedad particular y forma parte de los procesos de territorialización que están en la base del desarrollo entre territorio y cultura» (Bustos Cara, 2004, p. 11).

Así los C.T., en la territorialización de ellos mismos como expresión de la cultura, logran mediante la acción de su ciclo productivo (figura 1) compuesto del "ser", "el hacer" y "el saber hacer", trabajar como una estructura, en los términos de gestión como disciplina.

Donde la Gestión del Conocimiento es, en definitiva, la gestión de los activos intangibles que generan valor para la organización. La mayoría de estos intangibles tienen que ver con procesos relacionados de una u otra forma con la captación, estructuración y transmisión de conocimiento (Fundación Iberoamericana del Conocimiento, 2010, p. 3).

Los activos intangibles que consideran los C.T., son esenciales para poder evaluar la potencial factibilidad de su gestión, considerando como estos son parte de su proceso en el territorio y condicionan el "hacer", debiendo comprender sus propias estrategias de desarrollo y acción, para comprender dicho potencial.

Esta estrategia de acción de los C.T., que significan su expresión teórica, práctica y de proceso, conforman la lectura compleja de una realidad en todas sus estructuras que conforman su ciclo de producción, «esto es así porque se trata de un fenómeno sistémico: un sistema existe sólo mientras exista la conservación de lo que lo define» (Siemens, 2011, p. 35).

6. La visión de una empresa es el objetivo al que la propia empresa espera llegar en un futuro. Se trata de la expectativa ideal de lo que quiere lograr, indicando a dónde se dirige y cómo desea ser en el largo plazo. (www.economipedia.com) 


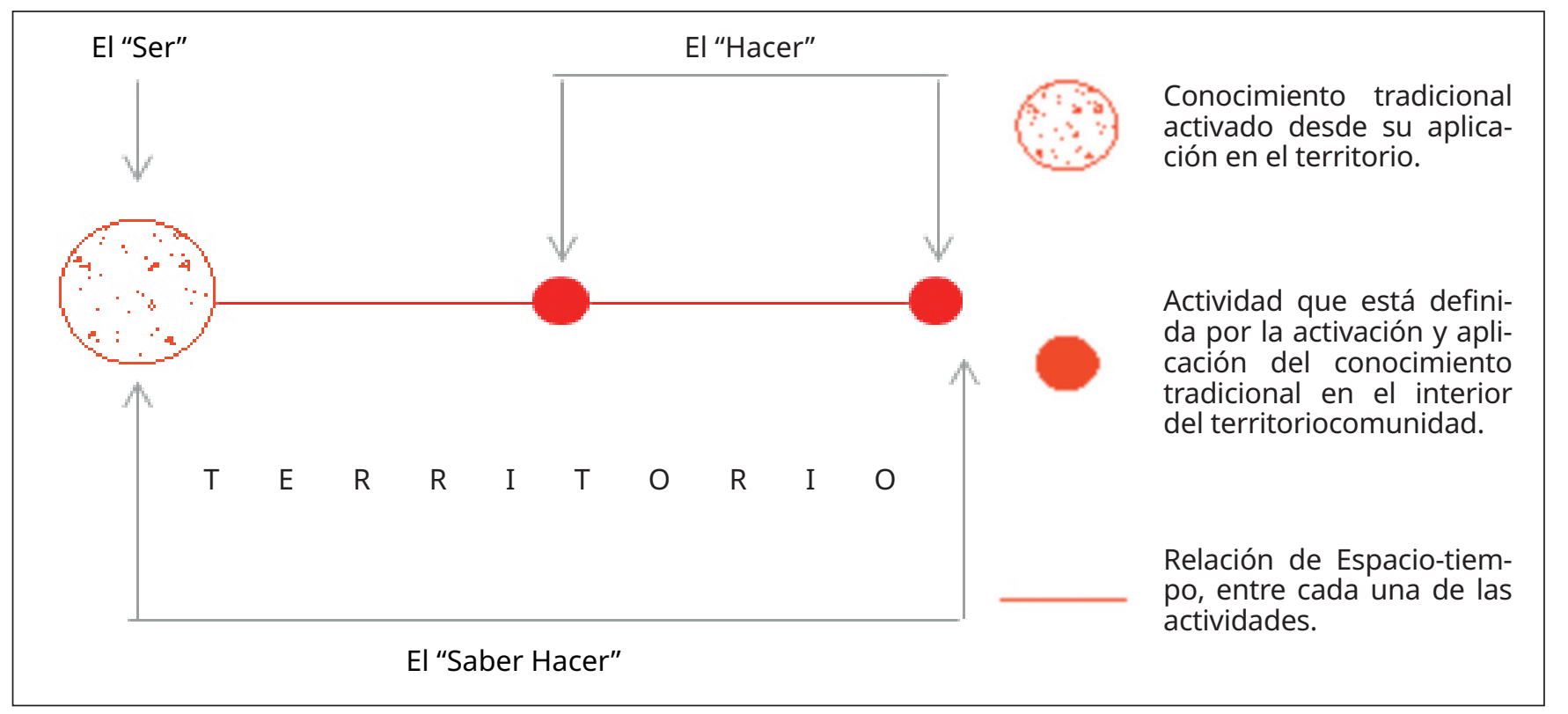

Figura 1. Ciclo productivo del C.T. Fuente: Autora.

Esta unidad sistémica que va entretejiendo la expresión de un conocimiento tradicional en el territorio, define al fenómeno que se debe gestionar, en las estructuras de su ciclo de producción, entendiendo como operan los activos intangibles de la totalidad para permitir la gestión de los C.T.

Para comprender esta unidad sistémica, se considera lo planteado por Romero Bedregal (2006) donde la clave que logra sostener el estado de equilibrio dentro de un fenómeno de este tipo, es la inserción del proceso de planificación en el sistema de gestión, que integra la dimensión eco-social, que combina la gestión ambiental, territorial, administrativa y económica.

La dimensión de este fenómeno y las interconexiones que lo definen en el territorio, desde el "hacer" son una de las primeras materias que nos entrega la posibilidad de verificar su factibilidad, para determinar el potencial de gestión de este conocimiento, como patrimonio y recurso para su comunidad. Esta evaluación en la primera fase que va dibujando la estrategia de gestión que se activara dentro de una comunidad, considera un «proceso que comenzando por la identificación de la idea, siguiendo por el estudio previo de factibilidad pretende reducir el riesgo y la incertidumbre del sacrificio de invertir en pos de determinados objetivos» (Lira, 2006, p. 19).

Considerando la necesidad de ser eficientes, en el manejo de los recursos se propone evaluar el levantamiento del fenómeno del conocimiento tradicional, enfocándonos en la intervención de la estructura del "hacer", que es la manifestación tangible del conocimiento dentro del territorio.

Dentro del desarrollo del espacio territorial de una comunidad, aparece su capital físico ${ }^{7}$ que es lo tangible y reconocido en el medio ambiente, el cual condiciona y potencia la generación del habitar de este hombre dentro de la naturaleza que lo contiene.

Comprende como capital, su patrimonio tangible que administra y gestiona, en la expresión cultural y ambiental del territorio. Dentro de esta unidad se distingue el capital natural que condiciona la subsistencia.

Estando el capital natural: constituido por la dotación de recursos naturales renovables (agua, aire, suelo, biodiversidad de flora y fauna), de recursos naturales no renovables (petróleo, carbón, gas natural, metales, minerales) y de servicios ambientales de los ecosistemas (ecosistemas naturales estratégicos, control de la contaminación, control de la erosión, preservación de la biodiversidad, regulación del clima, regulación del ciclo hidrológico,

7. Así es que la primera forma de capital que utilizaré en este análisis será el capital económico (a veces llamado capital físico o capital construido), esto es, el stock de recursos financieros que, período a período, está disponible para fines de inversión en cada región (Boisier, 1999, p. 43). 
regulación del ciclo del carbono, regulación del ciclo de nutrientes, regulación del oxígeno atmosférico, soporte de actividades antrópicas urbanas, rurales y sectoriales (Vega Mora, 2002, p. 3).

La forma en que esta comunidad condice este capital natural, al trabajarlo, simbolizarlo y transformarlo, va jerarquizando cada componente y moldeando su entorno para conformar su patrimonio tangible. En este moldear el territorio se puede ver condicionantes de uso histórico del entorno, acciones de valorización y un sistema de toma de decisiones que muestran el nivel de comunión que han construido con su espacio natural.

Desde esta racionalidad histórica (Romero Bedregal, 1980), han construido una expresión que les otorga un valor diferencial frente a otras comunidades, siendo la expresión de los C.T., el resultado del fenómeno complejo y que genera un programa de uso, que entrelaza al "ser" y al "saber hacer" sobre el territorio.

Es así como estas unidades sistémicas de los C.T., se pueden comprender como fenómenos complejos que entrelazan el espacio y tiempo del territorio, son articuladas como distintos contextos determinando el orden sistémico del territorio, este nivel de complejidad e interconexión, lo propone el concepto de patrimonio biocultural, que comprende a los «recursos naturales bióticos intervenidos en distintos gradientes de necesidad por el manejo diferenciado y el uso de los recursos naturales según patrones culturales» (Boege, 2008, p. 13).

Considerando al capital natural, que corresponde al capital físico y tangible que poseen las comunidades rurales e indígenas, como parte de su patrimonio biocultural, por lo cual, lo sitúa de forma integral en una unidad sistémica indivisible con los capitales intangibles administrados desde el habitar.

\section{METODOLOGÍA}

Para determinar este fenómeno sistémico que nos permitiría evidenciar la factibilidad de gestión de los C.T., debemos definir las actividades que constituyen el programa de uso y ocupación territorial, que comprenden unidades habitables, determinando en su sumatoria y sistema, la dimensión y alcance ambiental que los C.T., constituyen en el "hacer".

Para esto se definirán un esquema (figura 2) que comprende, a las actividades que son pertinentes a los C.T., estas actividades en sí mismas, cada una, conforman una unidad habitable, que en sí misma es un espacio-tiempo, la cual se conecta con otra actividad mediante otro espacio-tiempo, generando un encadenamiento territorial, el cual determina su expresión como patrimonio en la aplicación, la producción y desarrollo de la mutua colaboración con su entorno.

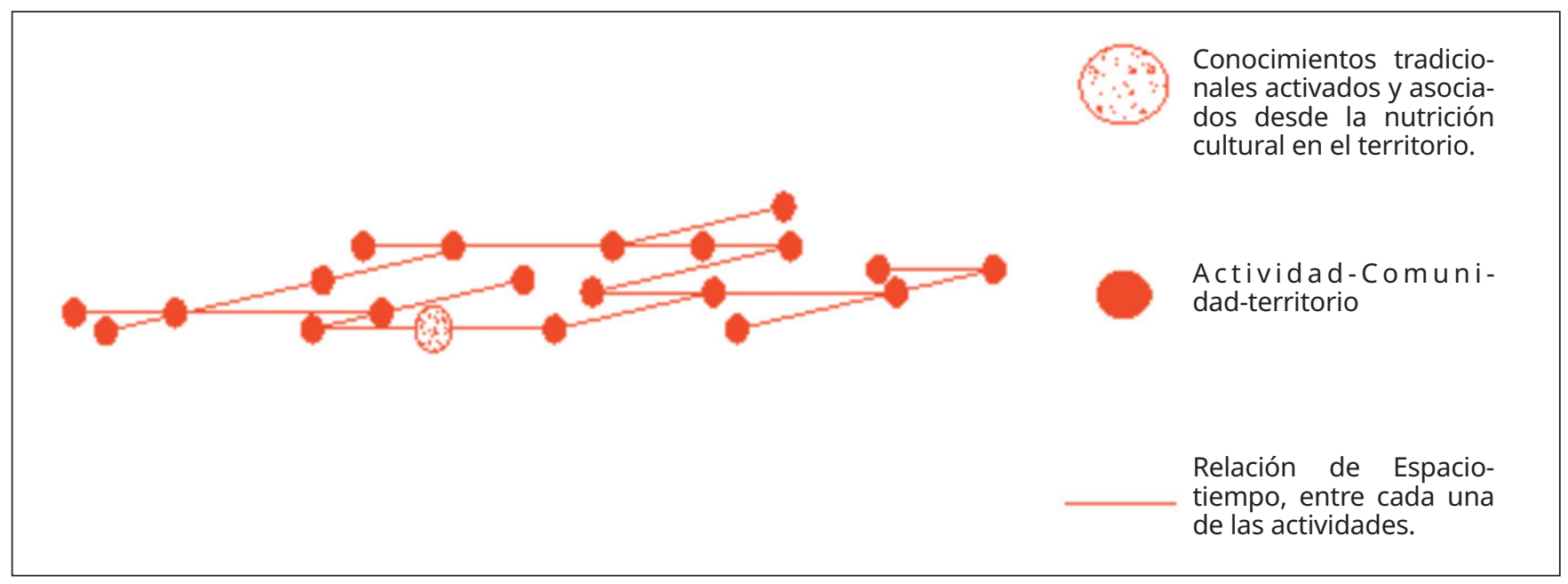

Figura 2. Alcance ambiental del habitar. Sistema correspondiente a las actividades locales, insertas en las unidades territoriales propias del conocimiento tradicional. Fuente: Rosas-Bustos, 2014, p. 61. 
Desde esta mirada en el proceso de patrimonialización y gestión estratégica de este conocimiento, se requiere entender el tejido, que conforma la sistémica de la función y su acción en el territorio. Así, se puede plantear desde la "Teoría General de Sistemas".

Donde según Von Bertalanffy (1996), es necesario estudiar no sólo partes y procesos aislados, sino también resolver los problemas decisivos hallados en la organización y el orden que los unifican, resultantes de la interacción dinámica de partes y que hacen el diferente comportamiento de éstas cuando se estudian aisladas o dentro del todo (p. 31).

Las resultantes de interacción dinámica y de coordinación, que existen entre las actividades, generan un sistema de encadenamiento de acción en el territorio, que determina unidades continuas, desde el enlace del tiempo-espacio, en el habitar específico que construyen los C.T., de cada cultura. La generación de estas unidades coordinadas, desde la activación de los C.T. en el territorio, determina una estructura que lo conforma en su forma y función.

Donde tanto en "estructuras" como en "funciones". En última instancia, estructura (orden de partes) y función (orden de procesos) pudieran ser la mismísima cosa: en el mundo físico la materia se disuelve en un juego de energías, y en el mundo biológico las estructuras son expresión de una corriente de procesos (Von Bertalanffy, 1996, p. 26).

Se conforma una corriente continua de procesos en el "hacer", determinando un soporte organizado que a su vez comprende a la función, que como sistema jerarquiza al territorio, que define como patrimonio a los C.T.

Esta unidad, se interconecta con otras unidades, donde se conforman las relaciones entre los C.T., las que en conjunto comprenden todas las expresiones culturales de una comunidad, las cuales han quedado plasmadas como un tejido de huellas vivientes, sobrevivientes e históricas de cada actividad en el territorio (figura 3).

Entender como la sistémica que entrelaza y relaciona a los conocimientos dentro de una comunidad, es considerar los distintos requerimientos de la gestión cultural que solicitan cada uno de estos, al sistema mayor.

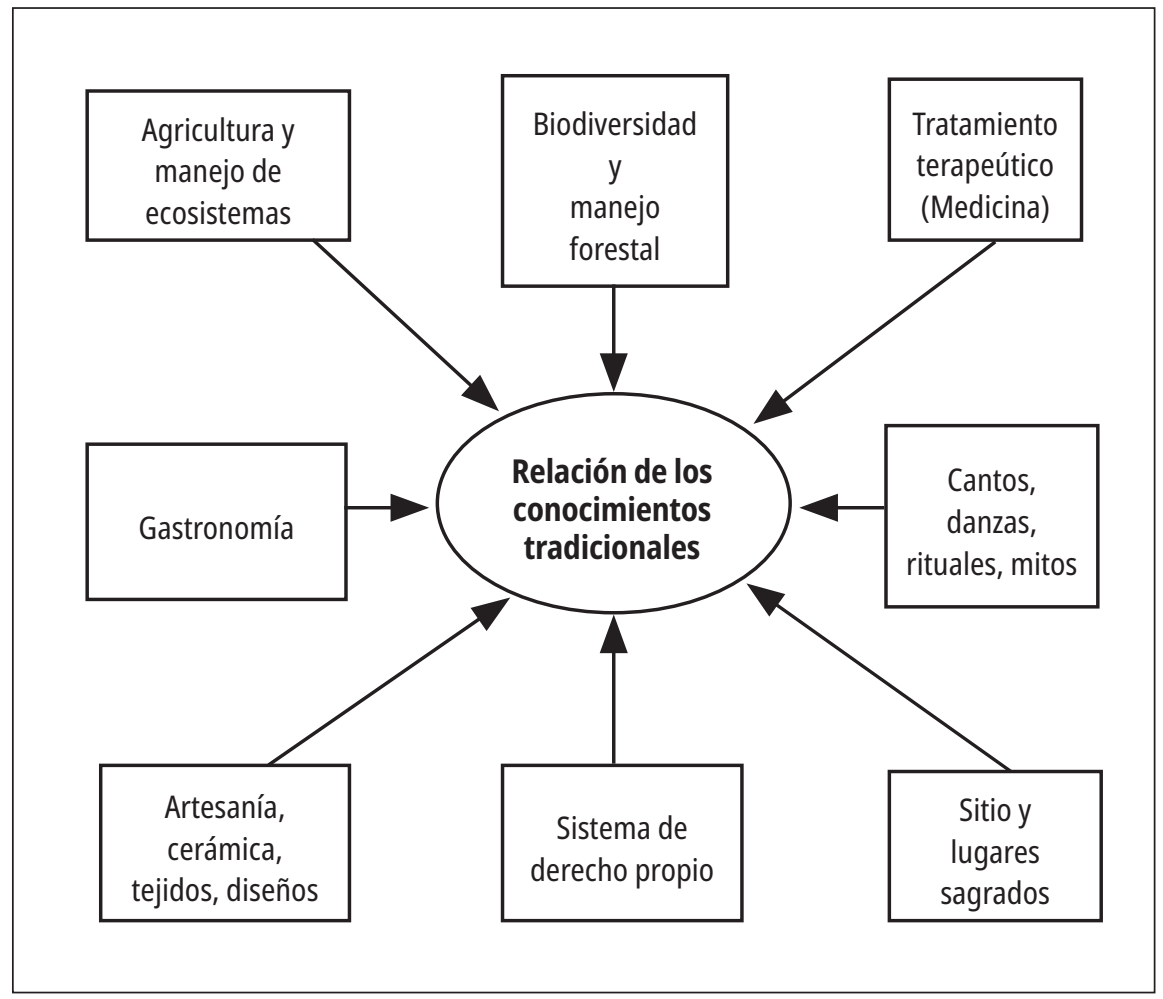

Figura 3. Relaciones de los conocimientos tradicionales. Fuente: Bolvito, Macario y Sandoval, 2008, p. 121. 
Al actualizar el valor de los C.T., como patrimonio para su comunidad y gestionarlo como recurso, se deben primeramente evaluar cuál es el estado de interrelación que tiene cada uno con el resto de los conocimientos. Debiendo definir así una trayectoria en el proceso de intercambio cultural local, que comprende la interconexión y relación entre cada uno de ellos. Definir este alcance territorial de los C.T. y la relación con otros conocimientos, podría aportar a la restitución cultural y de subsistencia de esta comunidad, creándose potenciales estrategias de recuperación.

Como lo consideran las experiencias agroecológicas campesinas e indígenas: en las regiones Andina Central, Andina Nororiental y Andina Sur de Colombia, han sido desarrolladas experiencias de organizaciones campesinas relacionadas con la producción agroecológica y la recuperación, uso y manejo de la biodiversidad como estrategias productivas para rehacer sus sistemas productivos (Cárdenas Grajales, 2010, p. 8).

Para determinar estas estrategias y así como también, evaluar la factibilidad de gestión de los C.T., se debe dimensionar el alcance de éstos, como se expuso en el anterior esquema (figura 3), al cual se suma la interrelación del conjunto de los C.T., que plantea la gestión cultural interna de la comunidad, definiendo el intercambio entre los C.T., sobre esta forma de interconexión se genera el siguiente esquema (figura 4).

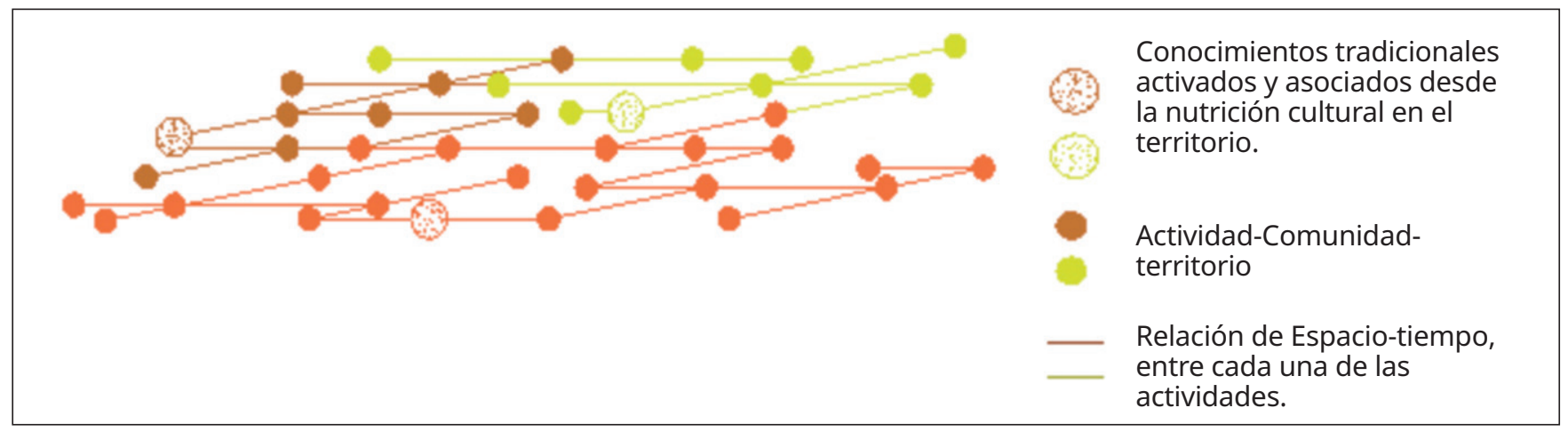

Figura 4. Intercambio y nutrición entre los conocimientos tradicionales. Fuente: Rosas-Bustos, 2014, p. 63.

Para poder verificar en un diagnóstico rápido, los modelos referidos a la unidad sistémica de un conocimiento tradicional que comprende su alcance territorial y la interrelación que se conforma entre los saberes de una comunidad y su territorio. Se tomarán dos casos de C.T., que muestren una realidad de comunidad indígena y una realidad de una comunidad rural. El primer caso, correspondiente al "Sistema Constructivo de viviendas de barro y paja, de la comuna de Colchane, región de Tarapacá norte de Chile." Este caso, se ubica en el extremo norte de Chile, en un paisaje de altiplano, donde habita la comunidad indígena Aymara, lugar contenido por el desierto, que es pampa, quebrada y costa.

El segundo caso, "Mesa de mujeres rurales de la comuna de Licantén, región del Maule, sur de Chile". Este se emplaza en un paisaje de bosques y ríos, con una serie de asentamientos productivos agrícolas, corresponde a una comunidad y organización rural.

Ambos casos nos permitirán realizar la aplicación de los modelos, para verificar de forma inicial la factibilidad de gestión sostenible de un C.T. dentro de su comunidad.

\section{RESULTADOS Y DISCUSIÓN}

\subsection{Sistema constructivo de viviendas de barro y paja, de la comuna de Colchane, región de Tarapacá norte de Chile}

Se consultará al siguiente caso, el cual está desarrollado a partir del conocimiento de un sistema constructivo de viviendas de barro y paja, el cual, es un saber del área rural e indígena Aymara, ubicada en la región de Tarapacá. 


\begin{tabular}{|c|c|c|}
\hline & Provincia & Capital \\
\hline
\end{tabular}

Figura 5. Gráfico y ubicación de comunas de la primera región de Tarapacá, norte de Chile.

Fuente: www.wikimedia.org

Esta comunidad habita en la comuna de Colchane, donde la provincia urbana más cercana es Iquique. A continuación, se describe el sistema constructivo que propone este saber tradicional.

El conocimiento tradicional que se observa en alcance sobre este territorio, se encuentra aplicado por la comunidad Aymara del sector, con el objetivo de poder construir viviendas... El sistema general comprende bases de mampostería en piedra, en sus muros adobe y/o piedra, en su cubierta se conforma por tierra cruda en paños, mezclada y aglutinada con paja brava, soportada por una estructura de queñuas ${ }^{8}$ amarradas con tripas y cueros de llamo (Rosas-Bustos, 2014, p. 340).

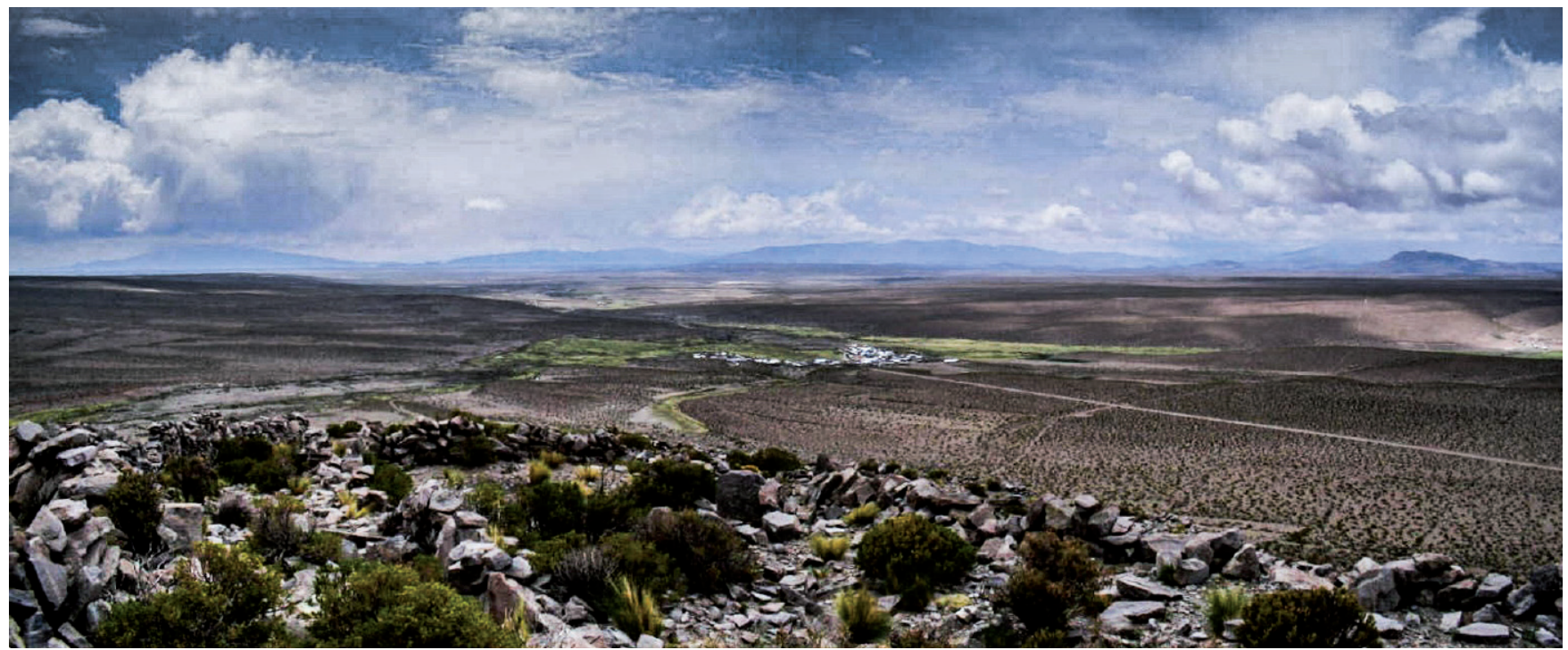

Fotografía 1. Unidad Territorio-Comunidad Local. Emplazamiento, pueblo de Isluga, comuna de Colchane. En este pueblo ceremonial, aún se mantiene algunas viviendas con techos de paja, con muros de tierra y piedras. Fuente: Autora. 


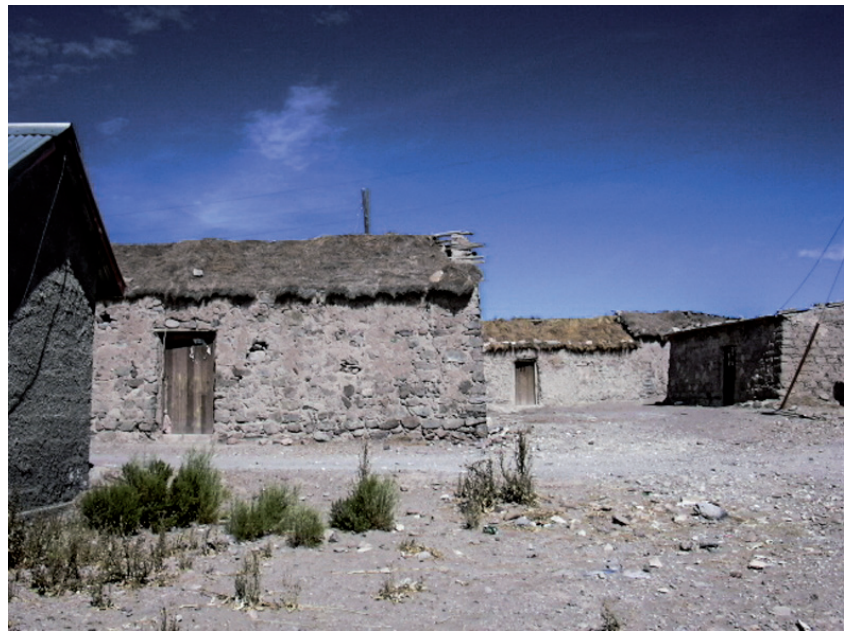

Fotografía 2. Conocimiento aplicado. Estructura exterior de la cubierta compuesta por paños depaja y barro apisonado, en vivienda de muros de piedra. Fuente: Autora.

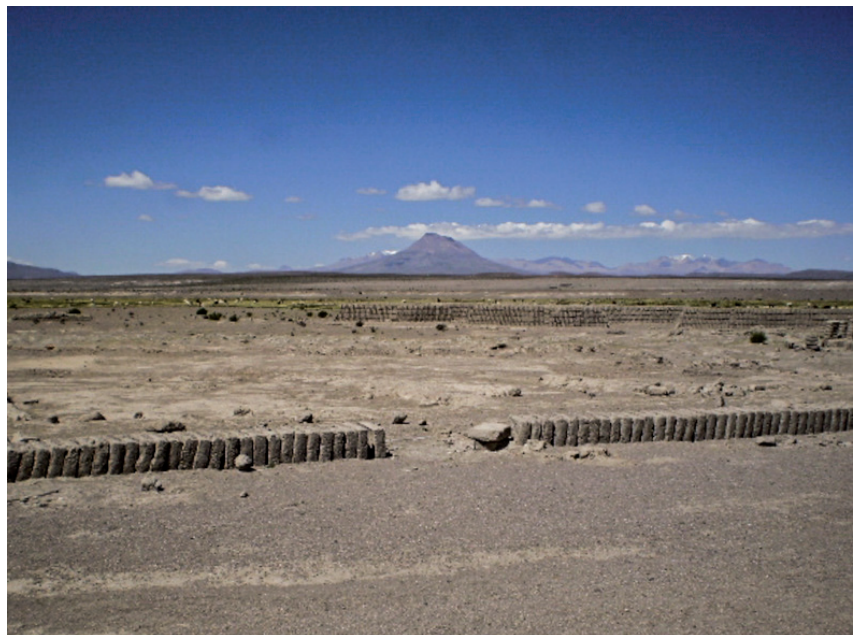

Fotografía 3. Parte del proceso. Después de la elaboración de adobes, de barro más paja aglomerada, se concluye con el secado, para apilar los bloques. Fuente: Autora.

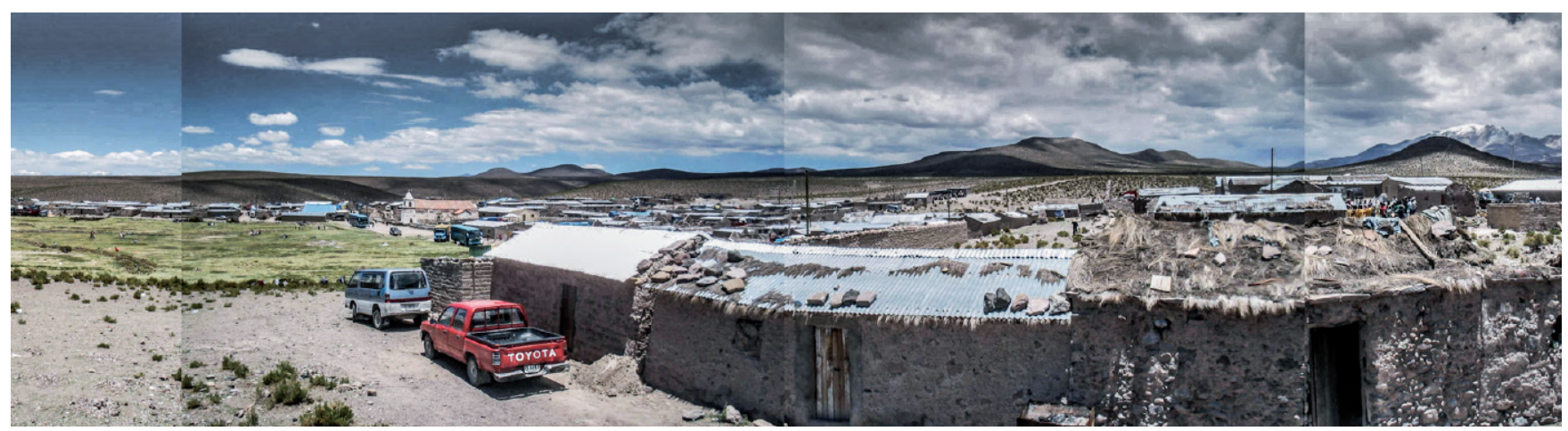

Fotografía 4. Contexto local actual. Poblado sagrado de Isluga, comuna de Colchane, construcciones actuales y antiguas. Fuente: Autora.

Como propone el Mancilla (2001), este sistema de poblados corresponde a la época hispánica, cuando la organización de la región de Tarapacá al finalizar el siglo XVI conformaba un espacio hacendal ubicado en los valles bajos, medios y de altura en la cordillera y el altiplano.

Actualmente, aún es observable este tipo de edificación de las viviendas y sus cubiertas en el área, en muy menor grado son ejecutadas respecto a la técnica de su periodo de auge histórico. Como sistema constructivo responde a una unidad ambiental, que se sitúa sobre los $3.500 \mathrm{msnm}$, su temperatura media no supera los $5^{\circ} \mathrm{C}$, considerando una gran amplitud térmica entre el día y la noche, con lluvias que no superan los $400 \mathrm{~mm}$ al año.

Por lo cual como construcción comprende la aislación del interior de la vivienda, de la incidencia climática inmediata, logrando mediante la implementación de materiales de la zona una aislación por capacidad a través del barro y la piedra, conteniendo la temperatura interior de un recinto, logrando un lugar fresco y controlado durante el día, conformando la contención del calor para el pernoctar durante la noche (Rosas-Bustos, 2014, p. 340).

El esquema comprende la unidad del alcance territorial de los C.T. (figura 2), se aplica a la técnica constructiva de las viviendas aymaras, donde cada acción o actividad que se desarrolló en el poblado de Isluga, que comprende la construcción de una vivienda tradicional, conforma el siguiente esquema (figura 6). 


\section{Conocimiento tradicional
activado y aplicado. \\ Recolección de queñua en los bosques. \\ Limpieza y definición de pie- zas de queñua para cubierta. \\ Tratamiento y amarre de paños de paja brava. \\ Recolección de paja brava en sectores altos de humedales.}

Figura 6. Sistema general correspondiente a las actividades locales propias del conocimientotradicional referido al sistema constructivo de adobe y piedra de las viviendas aymaras del pueblo de Isluga. Fuente: Rosas-Bustos, 2014, p. 66.

Actualmente, la técnica de construcción de viviendas de adobe con techo de paja y barro, está desapareciendo, la comunidad ha incorporado nuevos materiales y otras técnicas constructivas, que no incorporan la aislación térmica que aportaba el sistema original.

Esta situación ha generado un problema, ya que esta pérdida de los C.T. ha afectado principalmente a las cubiertas en las viviendas, donde han sido remplazados, la paja y el barro por planchas de zinc y aluminio, fijadas a un soporte de madera de pino o metal, traídos desde la ciudad. Estas cubiertas a veces han sido reforzadas con piedras sobre los muros para soportar los fuertes vientos de la zona (fotografía 5).

Estos cambios han surgido como consecuencias del proceso de trasformación de la cultura y las afecciones de la globalización en el altiplano chileno. Esto nos muestra la necesidad de la recuperación de esta técnica y sus conocimientos, para así recobrar este oficio tradicional.

Hoy en este territorio, existen viviendas de más de 150 años de antigüedad, las cuales en su mayoría se encuentran dañadas por seísmos, falta de mantenimiento y abandonadas por no existir mano de obra que pueda ayudar a recuperarlas.

Esto ha ocurrido principalmente, debido a lo que plantea Bolvito Macario y Sandoval (2008) las actuales generaciones que tienen la energía para sostener y desarrollar los largos procesos de tratamiento y recolección de materias primas, han emigrado a la ciudad.

Esto nos muestra que el alcance que constituyen los C.T., como patrimonio en un territorio, es directamente proporcional a la consumación de activos intangibles y materiales que determinan todas las actividades que conforman su "hacer".

Siendo este sistema de actividades en el "hacer", un tipo de organismo que sostiene la conservación y actualización de los C.T. el cual requiere

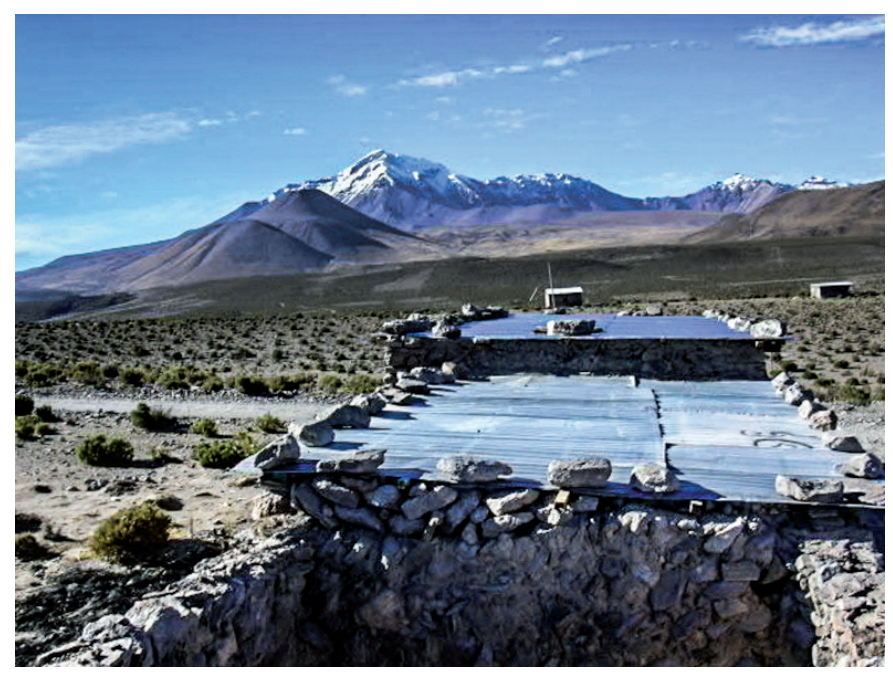

Fotografía 5. Viviendas de adobe con cubierta de planchas de zinc, clavas a en la estructuradecubierta y fijadas mediante piedras. Fuente: Autora. 
estar funcionando en toda la cadena de valor, para poder lograr el producto final como sistema, donde se considera como base para su funcionamiento al "ser" y "saber hacer", correspondiente a la comunidad, totalizando la estructura. Pues, un organismo y sistema según Von Bertalanffy (1996) sostiene una continua incorporación y eliminación de materia, constituyendo y demoliendo componentes, sin obtener durante su vida, un estado de equilibrio.

Cuando llega ese estado de equilibrio, se considera como uno de los C.T. que ha perdido su valor en la comunidad, ya que se ha detenido su función. Como podemos ver en el caso de estudio, donde al no contar con mano de obra, ni voluntad o visión de la organización que conforma la comunidad, la aplicación de este saber está en vías de desaparecer, dentro de su comunidad aymara.

Por lo cual también se han dañado las interconexiones e intercambios con otros conocimientos de la comunidad, en la sistémica del territorio, esto ha afectado a distintas actividades programáticas de uso patrimonial que pueden ser insumo y direccionar un sentido para la recuperación del territorio. La migración a la ciudad de estas comunidades, considera un replanteamiento de su unidad territorial.

En efecto, se ha visto que los cambios en las estructuras económicas, en las relaciones sociales de producción, hacen que los actores sociales construyan a los territorios de otra forma, motivo por el cual apreciamos que los espacios urbanos y rurales exhiben ahora diferentes características que las que tenían años atrás, características que reflejan la dinámica económica y cultural de la actual fase del capitalismo, es decir, diferentes formas de uso, y de apropiación material y simbólica del espacio por los actores, es decir, otras formas de organización territorial (Suárez, 2012, p. 6).

Esta situación, también ha afectado al desarrollo local, pues desde el punto de vista sistémico, según Boisier (2005) el crecimiento territorial es una función de la interacción del sistema y su entorno. Pues, al cesar la interacción en la actividad de parte del proceso de construcción de la vivienda, se han abandonado rutas, caminos y lugares, olvidando técnicas específicas que daban al conocimiento esta continuidad en su alcance.

Esto nos acerca a un diagnóstico rápido, sobre la potencialidad de gestión que tiene este C.T. como patrimonio y recurso para esta comunidad aymara. Demostrando que este alcance casi ya inexistente, como sistema de actividades continuas y entrelazadas en el territorio, no logra incorporar la aplicación de los activos intangibles y materiales.

Dejando sin operación a «las interacciones que trasforman una colección de elementos incordiados en un sistema coherente y funcional. Este aporte emergente resulta de las sinergias que se producen al entrar en contacto elementos anteriormente inconexos» (Boisier 2007, p. 78).

Esto sucede debido a que el "ser" comunidad, no lo considera en su visión como organización, observándose que la unidad sistémica, no cuenta con los capitales intangibles para mantener el hacer sobre el territorio. Esto nos lleva a visualizar una baja viabilidad y factibilidad de una inversión, que aporte a la recuperación de estos territorios desde el punto de vista del paisaje cultural.

Comprendiendo lo planteado por Romero Bedregal (2006), para la activación de los territorios, los objetivos que tienen que cumplirse, no son solo de producción como propone la economía, sino también de reproducción de las unidades biológicas, sociales y territoriales.

Esto dejo en evidencia, que el más importante requerimiento, es un trabajo previo, que restablezca su valor local, dentro de esta definición de "ser" comunidad, siendo el tema vital, la voluntad de la comunidad, antes de generar o desarrollar alguna estrategia para activar este conocimiento.

Pensamos que la comunidad, no es algo dado, independiente de la voluntad, un "lugar" en el que se nace, la familia a la que se pertenece o el barrio en el que se vive; la comunidad puede ser un deseo y, como tal, una construcción colectiva, deliberada, incesante, de un mundo mejor (Iglesias, 2015, p. 130).

Donde la voluntad de una comunidad, se basa en la visión ${ }^{6}$ colectiva que esta tiene como organización dentro de un proceso de gestión, pero también implica este concepto desde la perspectiva cultural y social, el cual se va formando en la toma de decisiones, desde su propia forma de generar conocimiento en el "saber hacer", por lo cual también desde su visión de mundo. «Este concepto no se refiere a una construcción 
personal o colectiva sobre la base del mundo de la vida y la experiencia vital sino a una concepción compartida que resulta del devenir del conocimiento humano» (Peñaloza,2015, p. 312).

De esta manera, un potencial paso siguiente, seria verificar como el "ser" se constituye respecto a este C.T., donde radica la voluntad y su visión de mundo actual como comunidad.

\subsection{Mesa de mujeres rurales de la comuna de Licantén, región del Muele, sur de Chile}

Para entender el valor de la nutrición e intercambio entre los C.T., en la interrelación que se conforma en una comunidad y territorio (figura 4).

Se cita a una organización que se estructura como comunidad, en asociación, llamada Mesa de Mujeres Rurales de Licantén.

La presidenta y gestora, Adriana Maureira, ha creado junto a sus socias, los proyectos y postulaciones a financiamiento, para el desarrollo de los conocimientos tradicionales y la creación de productos, que apoyan la subsistencia cultural, social, ambiental y económica de la comunidad a la que pertenece la organización, en la cuenca del rio Mataquito en la región del Maule, sur de Chile.

Donde los saberes y técnicas que van configurando, el "hacer", comprenden a la producción de mermeladas artesanales, el tejido en lana de oveja en el telar mapuche, la artesanía de artículos en conchas de mar, la agricultura orgánica y la artesanía en greda.

Los conocimientos de las mujeres de esta organización, se van desarrollando y complementando mutuamente desde su intercambio e interconexión. Esto se evidencia, ya que cada artesana sabe el arte de la otra, pero toma uno, como el más importante para su producción.

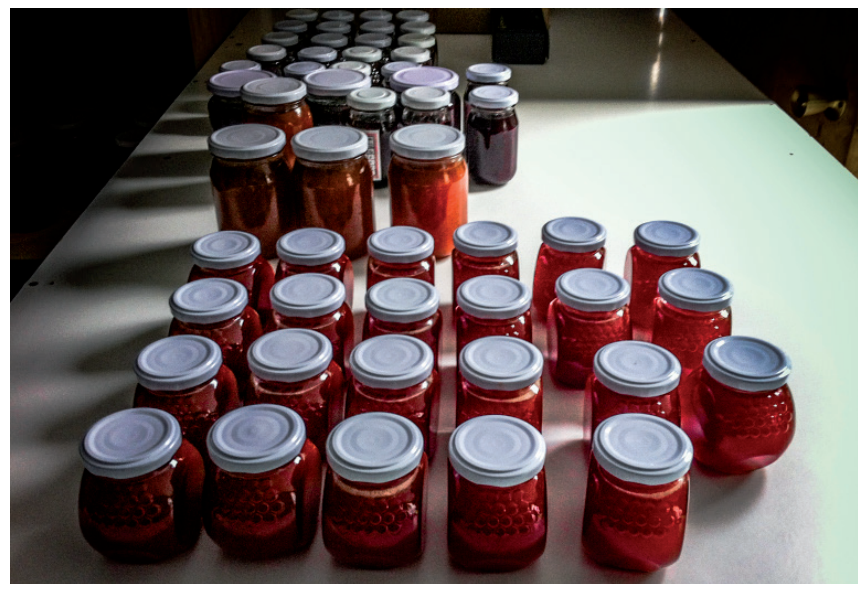

Fotografía 7. Mermelada artesanal. Fuente: Autora.

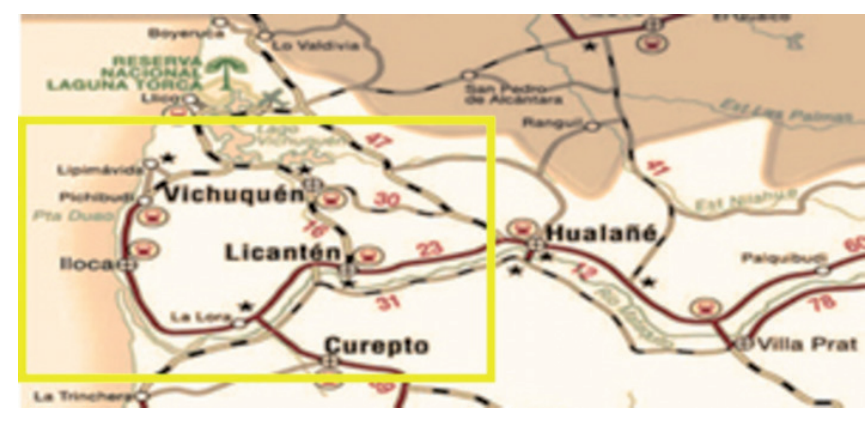

Figura 7. Unidad Territorio-Comunidad Local. Emplazamiento del territorio de operación de la organización de mujeres. Fuente: http://www.turismovirtual.cl/

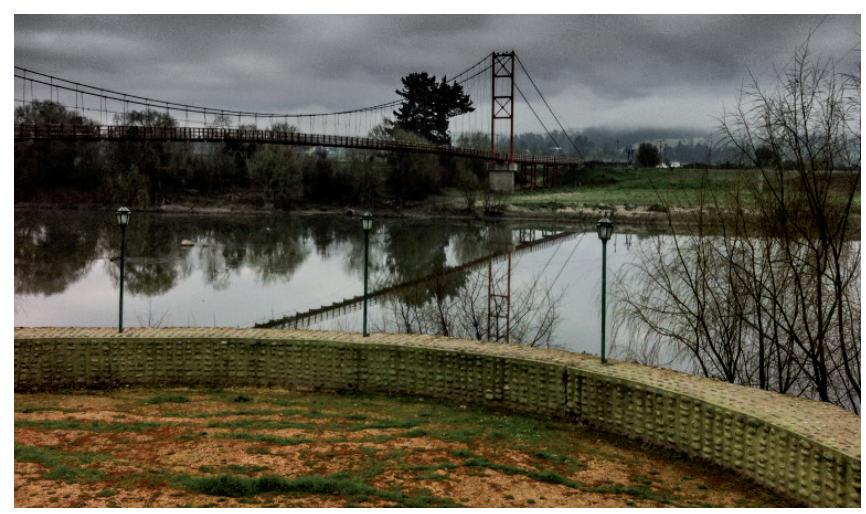

Fotografía 6. Visita del rio Mataquito desde el borde de la carretera y sector del centro cultural Pablo de Rokha. Fuente: Autora.

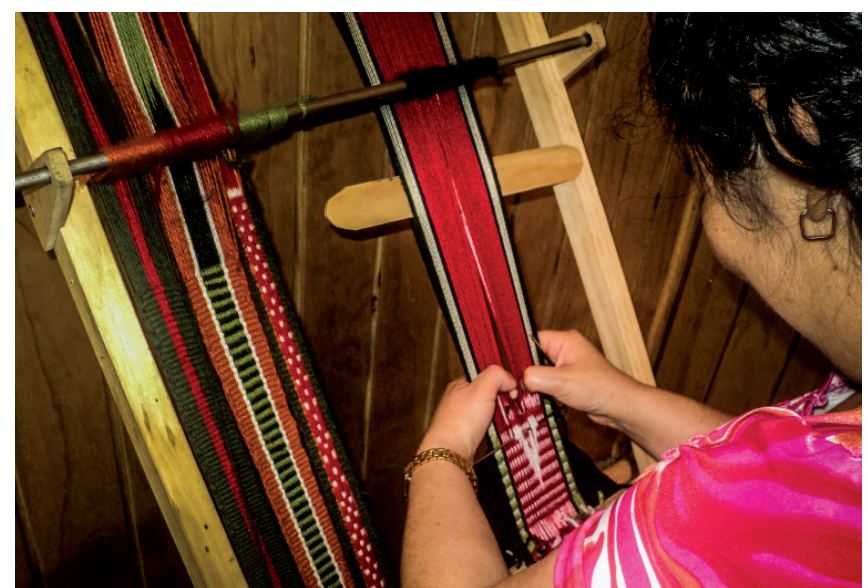

Fotografía 8. Tejido en telar Mapuche. Fuente: Autora. 


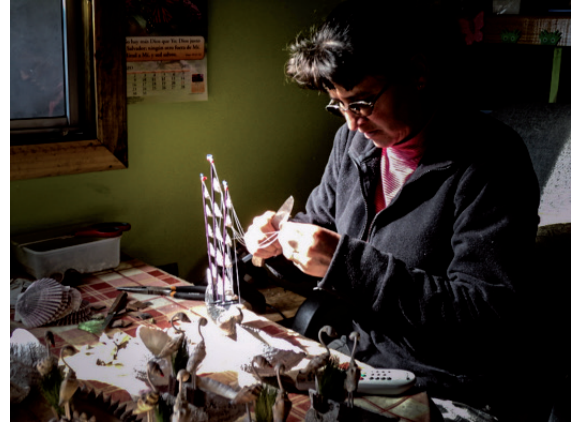

Fotografía 9. Artesanía en Conchas de mar. Fuente: Autora.

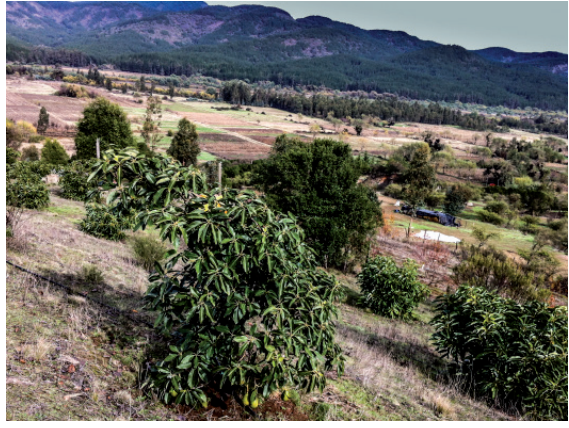

Fotografía 10. Agricultura orgánica. Fuente: Autora.

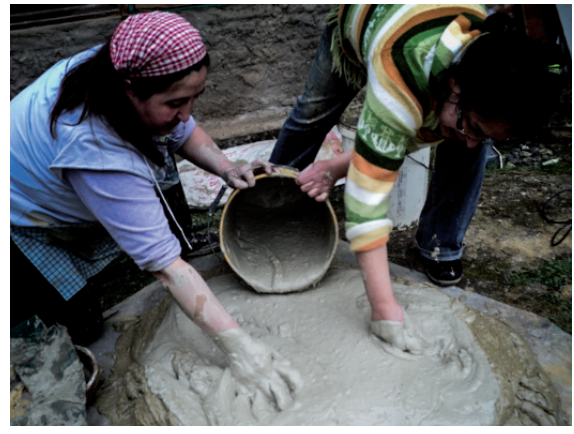

Fotografía 11. Agricultura orgánica de mar. Fuente: Autora.

El esquema que comprende el entrelazamiento de las actividades, el intercambio y la interconexión de los C.T. en el territorio (figura 4), se aplica al soporte que conforma esta organización y sus C.T., ocupando en su acción similares espacios, que se activan en cada "hacer", en la cuenca del rio Mataquito (figura 8). A partir de esta red surge la comercialización conjunta que han desarrollado como organización.

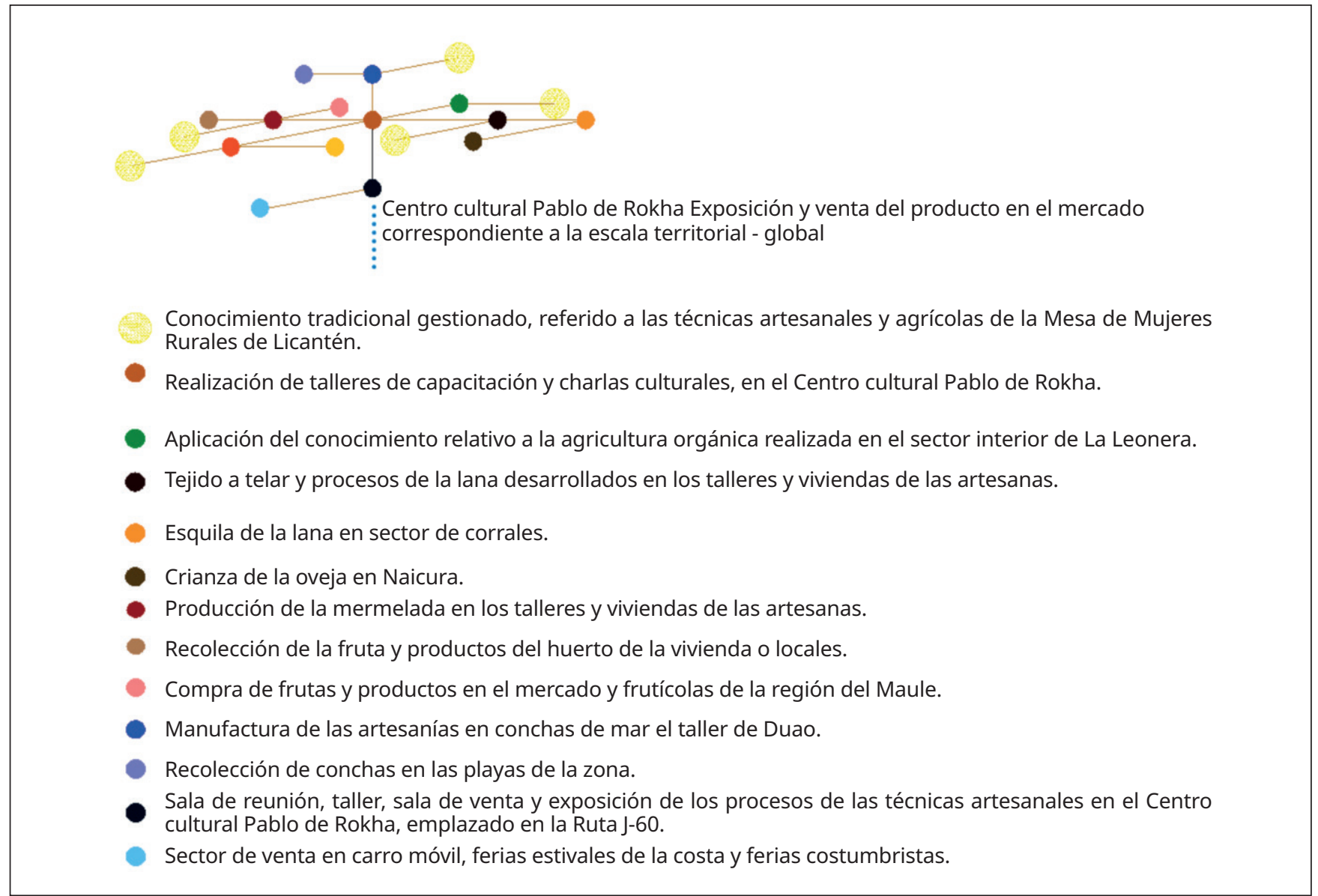

Figura 8. Sistema general correspondiente a las actividades que definen el alcance del proyecto de la Mesa de Mujeres Rurales de Licantén, define la activación de la unidad local y la estructura de conocimientos tradicionales en la zona de la cuenca del río Mataquito. Fuente: Rosas-Bustos, 2014, p. 466.

Esta unidad local y organización territorial, surge a partir de una serie de C.T. articulados en la producción de un territorio, que contiene una historia, podemos ver (fotografía 12), como entre los productos, se presentan intercambios de elementos y símbolos. 


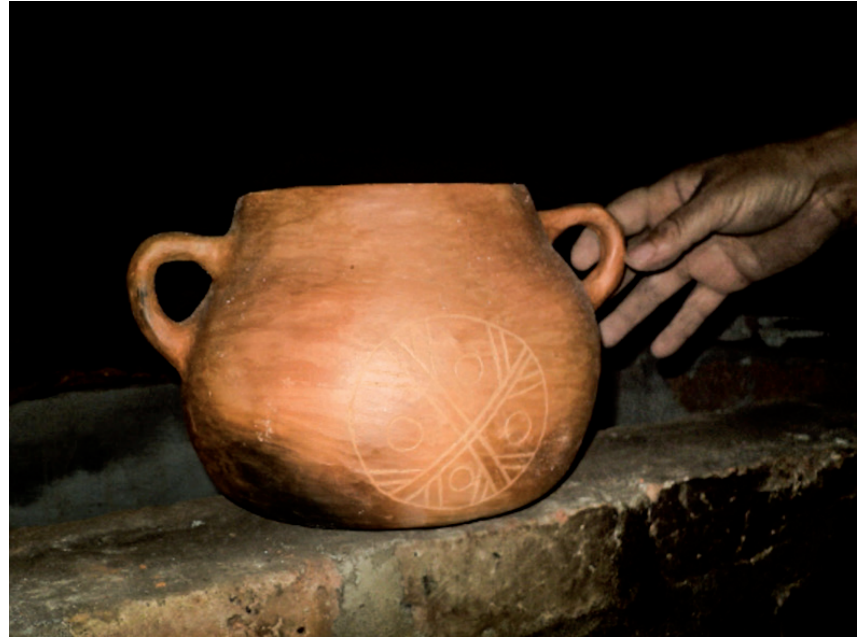

Fotografía 12. Vasija de greda en preparación con grabado del símbolo interpretado del cultrún mapuche Fuente: Adriana Maureira.

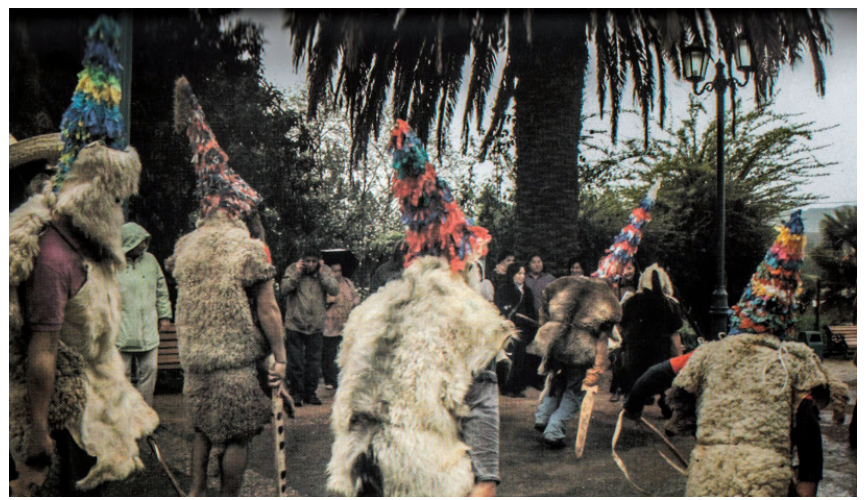

Fotografía 13. El baile del encuerado que protege a la virgen y las mujeres vestidas para el baile de los negros con sus respectivos atuendos. Fuente: Maureira y Calquín. 2012, p. 106.

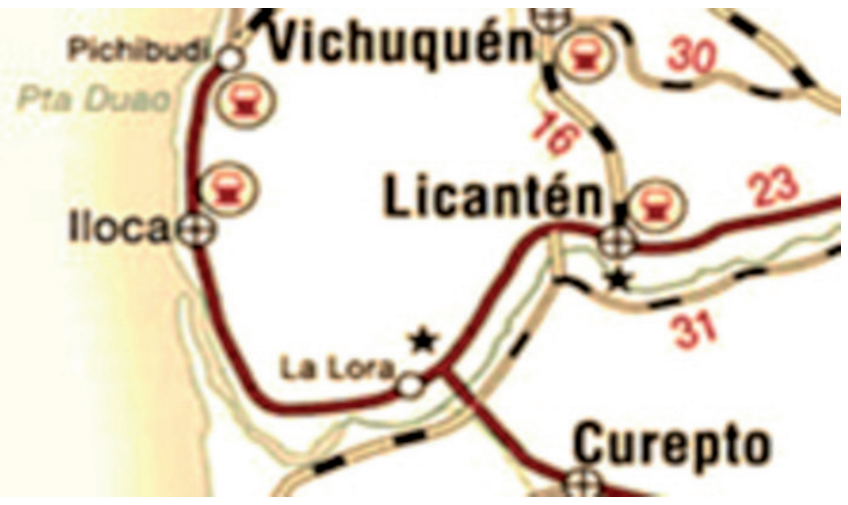

Figura 9. Plano de ubicación del territorio de Lora donde se realiza la fiesta del "baile de los negros". Fuente: http://www.turismovirtual.cl/

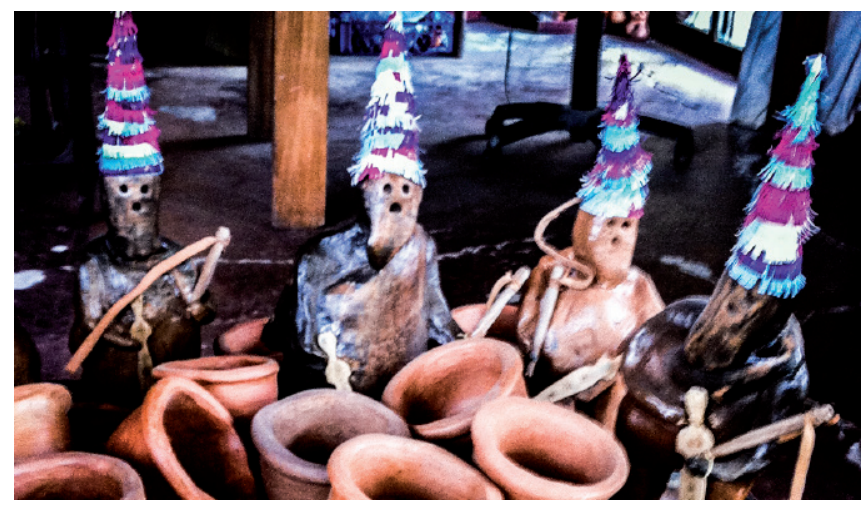

Fotografía 14. Figuras de greda que representan al encuerado personaje de la iconografía del "baile de los negros de Lora”, estas fueron realizadas por la señora Adriana Maureira, como producto artesanal de la Mesa de Mujeres Rurales de Licantén. Fuente: Autora.

Observamos como las artesanas en greda de Licanten, incorporan símbolos de los tejidos a telares e iconografía de origen Mapuche, dándole un sentido propio a la expresión de su arte desde su interpretación.

Otra muestra de intercambio entre los C.T., es la creación de los productos artesanales de alfarería, con la iconografía del encuerado, (fotografía 14), personaje que protege a la virgen del Rosario en la fiesta costumbrista de la cuenca del rio Mataquito llamado el "Baile de los negros de Lora", el cual celebra a la virgen del Rosario. Esta actividad religiosa y cultural, fue declarada tesoro humano vivo el año 2011, por el Consejo de Cultura y las Artes (CNCA) de Chile y la UNESCO.

Este grupo de artesanas, implementan en su acción y organización los C.T. que los hace factibles de gestionar, ya que logran en conjunto un intercambio territorial sostenido en el tiempo, exponiendo que el "hacer" en el territorio ha implementado su capital natural y físico, como unidad con los capitales intangibles administrados en su habitar.

Desde los capitales intangibles que se van haciendo una unidad con el capital físico y natural, logran materializar un capital psicosocial en su organización, el cual según Boisier (2004) se refiere a sentimientos, a emociones, a recuerdos, a "ganas de...", proponiendo una voluntad y visión del mundo desde el "Ser", que permite conducir cada interconexión para sostener la conservación, desarrollo e innovación en el marco que conforman los C.T. de esta organización dentro de la comunidad. 
Por otro lado, la existencia de capacidad empresarial innovadora a nivel local es, quizás, el elemento más decisivo para liderar el proceso de desarrollo y movilizar los recursos disponibles. La carencia de este componente fundamental para el desarrollo obliga a su "construcción social" (2016, p. 126-127).

La voluntad de innovar basada en una forma de organización, aporta al sostener el intercambio con su entorno, complementado cada uno de los C.T., permitiendo conformar un sistema abierto de colaboración que permite activar la innovación desde la estructura del "hacer", "ser" y "saber hacer", donde se acciona desde la reciprocidad.

El principio de reciprocidad es manifestación del principio de complementariedad en lo moral y lo práctico: cada acción recién cumple su sentido y fin en la correspondencia con una acción completaría, la cual restablece el equilibrio (transformado entre los actores sociales (Van Kessel,1997, p. 52).

Otro factor que permite la factibilidad de gestión de estos C.T., sosteniendo el "hacer" en el territorio, es el valor de otro capital intangible que surge del "ser" comunidad, el capital organizacional que según lo que propone Boisier (2004) es la inteligencia organizacional, por lo cual, la capacidad de monitorear el entorno mediante sensores y la capacidad de aprender de la propia experiencia, en el proceso de relacionamiento con el entorno.

Estas mujeres por sí mismas, en la experiencia y la necesidad de su subsistencia, han conformado una estructura organizacional que les permite funcionar y avanzar en el desarrollo de nuevos productos, viendo una riqueza en el encuentro con otras actividades culturales en su territorio. Aportando así, al desarrollo endógeno de su comunidad, comprendiendo que, según Vivas, Rodríguez y Mendoza de Ferrer (2010), a partir de las interacciones debidamente canalizadas, que se den en lo local, es lo que hará viable que el desarrollo endógeno sea conducente a un cambio sociocultural, propiciador de interacciones satisfacientes, producto de la selección del propio colectivo.

Dentro de los términos de la gestión, este desarrollo endógeno, demuestra el trabajo de los capitales intangibles de forma eficiente, en la sistémica que debe existir en la conformación correcta de una organización, donde se puede considerar a esta, como una estructura de intercambio, de actos y actividades entrelazadas, que cuentan con «la retroalimentación positiva para la sociedad y el entorno, y la integración de los enlaces y cadenas de valor para garantizar la evolución y supervivencia» (Bonel Cerdán, Bonel Cerdán y Fontaneda González, 2002, p. 343).

Comprender esta retroalimentación, nos permite verificar que esta serie de C.T. en este caso, son factibles de gestionar, al ser insumos activos en el funcionamiento de la comunidad como organización en su sistema territorial.

Ahora bien, tanto la constitución de redes, como la gestión del conocimiento que involucra la capacidad de aprender, generar y administrar el conocimiento y los aprendizajes de un espacio como mecanismos claves para construir o fortalecer una visión conjunta de estrategia territorial, requieren mecanismos que "faciliten" espacios de diálogos, reflexión, diseño e intervención entre actores e instituciones territoriales (2014, p. 142).

Es un factor necesario el encuentro de la comunidad, para activar la innovación y mantener la interconexión y la retroalimentación positiva de la organización.

En el caso de la Mesa de mujeres rurales de la comuna de Licantén, esta cuenta con un espacio que es sala de venta y exposición de los procesos de las técnicas artesanales en el Centro cultural Pablo de Rokha, es en este lugar donde se dan los encuentros colaborativos entre mujeres, también se dan los talleres de perfeccionamiento e intercambio, que han mantenido el desarrollo y el funcionando de la organización. Siendo su emplazamiento en la carretera de la Ruta J-60, un espacio de reunión, conexión y articulación territorial, ya que es un lugar accesible, tanto para otras comunidades, turistas y visitantes, como para las mujeres que son miembros de la organización.

El territorio y su programa de uso general, es un soporte necesario, para la activación y el desarrollo de los espacios pertinentes a cada C.T. uniendo los capitales tangibles e intangibles, con que cuentan las comunidades y organizaciones, creando un sistema total, que se puede entender desde lo que significa el capital territorial. Considerando que, «el capital territorial se entiende como la dotación ampliada del conjunto de 
recursos, bienes, conocimientos, capacidades, valores intangibles y capacidad de adaptación social» (TrujiIlo, Eraso y Loaiza, 2018, p. 58).

Esto nos muestra que el valor sistémico, de este contexto territorial, aporta como base general a los intercambios de interconexión y entrelazamiento que requieren las actividades y los espacios de un C.T. para funcionar, dentro del tejido que requiere el "hacer". Dentro del ámbito de la gestión, aporta a la generación de factibilidad de un conocimiento, para ser gestionado.

\section{CONCLUSIONES}

Desde el requerimiento de buscar estrategias de gestión de los C.T. que signifiquen la activación de estos, como patrimonio y recurso para las comunidades indígenas y rurales, se propone una definición operativa de los C.T. La cual, comprende al ciclo de producción de los C.T. dentro de un territorio, el cual está configurado en las estructuras del "ser", el "hacer" y "el saber hacer", desde esta definición, se pueden implementar estrategias como un medio, para crear caminos posibles de una gestión sostenible de este patrimonio.

Desde la estructura, se propone el "hacer", que sitúa al C.T. como un organismo, en acción y reacción con el territorio, propiciando el intercambio con otros C.T., permitiendo una interconexión y entrelazamiento que conforma una cadena de valor, que permite la nutrición entre cada uno de ellos.

El comprender el alcance de cada saber y su sistema de interacción, son pasos necesarios previos, para vislumbrar la factibilidad de gestión que tienen cada uno. Para así tomar, la decisión de definir los pasos a seguir, pudiendo también determinar dónde y con qué proyecto de recuperación o innovación, es más factible invertir para asegurar retornos en el ámbito social, cultural, ambiental y económico para las comunidades.

Considerando también lo que cada C.T. conforma una unidad sistémica compleja, la que puede aportar a esta nueva era del conocimiento, dentro de una globalidad que adolece de una visión integral de desarrollo.

Se cita el caso de estudio referido al «Sistema Constructivo de viviendas de barro y paja, de la comuna de Colchane, región de Tarapacá norte de Chile». Donde se verifico que el conocimiento actualmente no se encuentra funcionando en su alcance territorial, condicionando que, si no se genera el restablecer interno de valor que la comunidad le otorga a este C.T., la puesta en valor patrimonial o proceso de patrimonialización, no apoyará al ciclo productivo de las estructuras que lo componen, lo cual propiciara una acción no sostenible por la comunidad. A pesar del valor que este conocimiento puede tener para un sistema mayor de intercambio o para la conservación del patrimonio arquitectónico tradicional de esta comunidad Aymara.

Considerando que esta es una evaluación general y de aproximación, debido a que para continuar el desarrollo del método, el paso siguiente seria, acercarse a la comunidad, para verificar la voluntad de esta, frente a la generación de potenciales caminos de reetnificación o reactivación del desarrollo de este C.T., que estén en el deseo de la organización de esta comunidad.

En el caso siguiente, correspondiente a la «Mesa de mujeres rurales de la comuna de Licantén, región del Muele, sur de Chile». Se verifico que, mediante la aplicación del esquema de interconexión e intercambio entre conocimientos, los vínculos que existían y que se extienden en el territorio donde funciona esta organización, hacen factible la inversión de recursos para desarrollar un proceso de gestión sostenible en este territorio. Debiendo a continuación evaluar las actividades y espacios comunes que fortalecen esta interconexión e intercambio, para así destinar las siguientes estrategias de gestión que generen nuevas actividades o desarrollo de proyectos que aporten a la conversión de estos C.T. en patrimonio y recursos para el desarrollo de esta comunidad.

\section{REFERENCIAS}

Ballart, J. y Tresserras, J. (2001). Gestión del Patrimonio Cultural. Barcelona, España: Ariel S.A.

Boege, E. (2008). El patrimonio biocultural de los pueblos indígenas de México, Hacia la conservación in situ de la biodiversidad y agrodiversidad en los territorios indígenas. Edición Instituto Nacional de Antropología e Historia, Comisión Nacional para el Desarrollo de los Pueblos Indígenas, México. 
Boisier, S. (1999). El desarrollo territorial a partir de la construcción de capital sinergético. Revista Brasileña de Estudios Urbanos Regionales, 2, 39-53. https://doi.org/10.22296/2317-1529.2000n2p39

Boisier, S. (2005). ¿Hay espacio para el desarrollo local en la globalización? Internet, Revista de la CEPAL, 86. Agosto. https://doi.org/10.18356/8a88036d-es

Boisier, S. (2007). Territorio, estado y sociedad en chile. La dialéctica de la descentralización: entre la geografía y la gobernabilidad (Tesis doctoral). Universidad De Alcalá, Facultad de Ciencias Económicas y Empresariales, España. Recuperado de http://dspace.uah.es/jspui/bitstream/10017/2113/1/TESIS\%20SBOISIER\%20VERSION\%20FINAL.pdf.

Boisier, S. (2004). El Desarrollo Territorial a Partir de la Construcción de Capital Sinergético. Recuperado de http://www. perm.org.ar/biblioteca/articulos/del_\%20desarrollo_territorial....pdf, 12

Bonel Cerdán, J. I., Bonel Cerdán, F. J. y Fontaneda González, I. (2002). Nuevo Modelo de Creación de Valor para la Nueva Economía-Dinamizando el Modelo Delta. Internet, II Conferencia de Ingeniería de Organización. Universidad de Burgos, Escuela Politécnica Superior, Departamento de Ingeniería Civil. Área de Organización de Empresas. Recuperado de http://adingor.es/congresos/web/uploads/cio/cio2002/estrategia_competitividad_innovacion/C041.pdf

Bolvito, J., Macario, T. y Sandoval, K. (2008). Guatemala y su biodiversidad, un enfoque histórico biológico cultural y económico, consejo de aéreas protegidas. $1^{\text {a }}$ Reunión Latinoamericana de Análisis de Redes Sociales, Univ. Nacional de La Plata, La Plata, Argentina. Recuperado de www.analisisredes.com.ar

Bustos Cara, R. (2004). Patrimonialización de valores territoriales. Turismo, sistemas productivos y desarrollo local. Aportes y Transferencias, 8 (002). Universidad Nacional Mar del Plata, Argentina.

Bustelo, C. y Amarilla, R. (2001). Gestión del conocimiento y gestión de la información. Revista PH, Instituto Andaluz del Patrimonio Histórico, España. https://doi.org/10.33349/2001.34.1153

Briones, C. (1996). Culturas, identidades y fronteras: una mirada desde las producciones del cuarto mundo. Revista de ciencias sociales, 5, 121-133. Disponible en RIDAA-UNQ Repositorio Institucional Digital de Acceso Abierto de la Universidad Nacional de Quilmes. Recuperado de http://ridaa.unq.edu.ar/handle/20.500.11807/1440

Cárdenas Grajales, G. I. (2010). El Conocimiento Tradicional y El Concepto de Territorio. Profesora de Agroecológica Tropical Andina da UNISC - COLÔMBIA NERA - Núcleo de Estudios, Pesquisas e Proyectos de Reforma Agraria. Recuperado de www.fct.unesp.br/nera, 2, 8.

Drucker, P. (1969). The Age of Discontinuity. New York: Harper \& Row. https://doi.org/10.1016/B978-0-434-90395-5.50018-3

Fundación Iberoamericana del Conocimiento (2010). Introducción Conceptual a la Gestión del Conocimiento. Recuperado de http://www.gestiondelconocimiento.com/introduccion.htm

Goya, D., Vrsalovic, J. y Sainz, N. (2010). Redes de Innovación como factor de desarrollo económico. Chile: Universitarias de Valparaíso (Ed.).

Gutiérrez, S. (2016). Capital social, cultura organizacional, cultura innovadora y su incidencia en las Organizaciones Productivas Rurales Colaborativas. Pensamiento Crítico Latinoamericano, 20 (34), 119-136. Recuperado de https://dialnet.unirioja.es/servlet/articulo?codigo=5612531, 126-127.

Iglesias, M. (2015). Volver a la "comunidad" con Karl Marx. Una revisión crítica de la dicotomía comunidad-sociedad. Araucaria. Revista Iberoamericana de Filosofía, Política y Humanidades, 34, 109-132. Año 17. Segundo semestre de 2015. Recuperado de https://idus.us.es/bitstream/handle/11441/48052/1413-3785-1-PB.pdf?sequence=1\&isAllowed=y https://doi.org/10.12795/araucaria.2015.i34.06

Lira, L. (2006). Revalorización de la planificación del desarrollo. Santiago, Chile: Instituto Latinoamericano y del Caribe de Planificación Económica y Social (ILPES), Área de Gestión del Desarrollo Local y Regional, CEPAL. Recuperado de https://repositorio.cepal.org/bitstream/handle/11362/7316/1/S0600462_es.pdf

Lira, P. (2010). Redes de innovación en el marco de la teoría de la organización. Un enfoque desde lo social, Innovación y Creatividad. Recuperado de https://www.gestiopolis.com/redes-de-innovacion-en-teoria-de-la-organizacion-un-enfoque-social/

Llanes-Font, M., Isaac-Godínez, C., Moreno-Pino, M. y García-Vidal, G. (2014). De la gestión por procesos a la gestión integrada por procesos. Recuperado de http://scielo.sld.cu/pdf/rii/v35n3/rii02314.pdf

Mancilla, R. (2001). Memoria: Estudio Plan seccional localidad de Colchane y Pisiga Carpa. Gobierno de Chile, Ministerio de Vivienda y Urbanismo. (Ed.).

Maureira, A. y Calquín, H. (2012). En búsqueda de la Iconografía de la provincia de Curicó, cuenca del Mataquito. Chile: Gobierno Regional del Maule. 
Morín, E. (2006). El método 6 Ética. España: Ediciones Cátedra.

Peñaloza, G. (2015). Una mirada desde la Didáctica de las Ciencias al concepto de visión del mundo. Educ. Humanismo, 17 (29), 308-320. Universidad Simón Bolívar, Barranquilla, Colombia. https://doi.org/10.17081/eduhum.17.29.1259

Pokolenko, A. A. (2014). La gestión del conocimiento en el desarrollo territorial: procesos de investigación acción aplicados al desarrollo productivo del sector de la yerba mate y forestoindustria de la microrregión norte de misiones. Revista electrónica DRd. Desenvolvimento Regional em debate, 4 (2), 40-157. https://doi.org/10.24302/drd.v4i2.685

Restrepo, R. (1998). Cosmovisión, Pensamiento y Cultura. Revista Universidad Eafit, 34.

Rodríguez, J. (2008). Distribución espacial, migración interna y desarrollo en América Latina y el Caribe. Revista de la CEPAL, 96 diciembre. https://doi.org/10.18356/cd7c0ed5-es

Romero Bedregal, H. (1980). Movimientos sociales y planeamiento andino en Bolivia. La Paz, Bolivia: Camarlinghi.

Romero Bedregal, H. (2006). América Mágica simbiosis de cantos y ecuaciones. La Paz, Bolivia: Plural (Ed.).

Rosas-Bustos, C. (2014). Gestión del conocimiento tradicional como recurso patrimonial activo, en la función cultural y ambiental del territorio. (Tesis Doctoral). Universidad de Sevilla. Departamento de Historia, Teoría y Composición Arquitectónicas, España. Recuperado de https://idus.us.es/xmlui/handle/11441/24255

Soria, C. (2011). Las plataformas tecnológicas en Europa y España. Una iniciativa para la transferencia de conocimiento aplicado a la economía y el territorio. Revista de Estudios Andaluces, 28, 55-69. https://doi.org/10.12795/rea.2011.i28.04

Sachs, W. (2002). Globalización y sustentabilidad. Programa Chile Sustentable, Propuesta Ciudadana para el Cambio, Fundación Henry Dunat, Chile. Recuperado de http://fundacionhenrydunant.org/images/stories/biblioteca/derechos_ economicos_sociales_culturales_ambientales/Globalizacion_y_Sustentabilidad.pdf

Siemens, G. (2006). Conociendo el conocimiento. Recuperado de http://www.nodosele.com/editorial, Londres, Inglaterra, traducción.

Suárez, S. (2012). Globalización y territorios rurales: estímulo para el desarrollo territorial rural. Antología de Estudios Territoriales. Fomento de los Estudios Territoriales en Iberoamérica, Tercera Parte. Recuperado de http://repositorio. geotech.cu/jspui/handle/1234/3852

Trujillo, C., Eraso, F. y Loaiza, P. (2018). La sostenibilidad del capital territorial: propuesta metodológica para su análisis y valoración. Entramado, 14 (2), 50-72. https://doi.org/10.18041/1900-3803/entramado.2.4744

Van Kessel, J. (1997). Antropología andina. CIDSA, Iquique, Chile -- Puno, Perú.

Varela, R. (2001). Innovación empresarial: arte y ciencia en la creación de empresas. Bogotá, Colombia: Pearson Educación.

Vivas, A., Rodríguez, M. y Mendoza de Ferrer, E. (2010). Desarrollo endógeno, opción para el rearme humanizado del sistema productivo latinoamericano. Recuperado de http://www.scielo.org.mx/pdf/cya/n231/n231a2.pdf

Vega Mora, L. (2002). Hacia un diagnóstico territorial bajo enfoque sistémico. Revista Innovar. Recuperado de http://www. scielo.org.co/pdf/inno/v12n20/v12n20a04.pdf

Von Bertalanffy, L. (1996). Teoría General de los Sistemas. Edición Fondo de Cultura Económica México. Recuperado de https://cienciasyparadigmas.files.wordpress.com/2012/06/teoria-general-de-los-sistemas-_-fundamentos-desarrollo-aplicacionesludwig-von-bertalanffy.pdf

UNESCO (2003). Lenguas y Multilingüalismo. Recuperado de http://portal.unesco.org/science/es/ev.php URL_ ID $=5178 \&$ URL_DO=DO_TOPIC\&URL_SECTION=201.html

\section{PÁGINAS WEB}

Fundación Wikimedia. Queñua, Gráfico y ubicación de comunas de la primera región de Tarapacá, norte de Chile. Recuperado de https://www.wikimedia.org.

Diccionario económico Economipedia. Mision, Visión. Recuperado de https://economipedia.com.

Diccionario económico mytriplea. Rentabilidad de una inversión. Recuperado de https://www.mytriplea.com/diccionario-financiero/rentabilidad-empresarial/

Fondos de Cultura - Ministerio de las Culturas, las Artes y el Patrimonio. FONDART. Recuperado de https://www.fondosdecultura.cl/

Empresa de promoción turística. Plano región del Maule. Recuperado de http://www.turismovirtual.cl/

Comisión Económica para América Latina y el Caribe (CEPAL). Índices de urbanización en América Latina. Recuperado de https://repositorio.cepal.org/bitstream/handle/11362/41974/1/S1700257_es.pdf 